\title{
Investigational approaches for mesothelioma
}

\author{
Veerle F. Surmont ${ }^{1}$, Eric R. E. van Thiel ${ }^{2}$, Karim Vermaelen ${ }^{1}$ and Jan P. van Meerbeeck ${ }^{1 *}$ \\ 1 Department of Respiratory Medicine, Ghent University Hospital, Ghent, Belgium \\ 2 Department of Respiratory Medicine, Albert Schweitzer Hospital, Dordrecht, Netherlands
}

\author{
Edited by: \\ Masahiro Tsuboi, Kanagawa Cancer \\ Center, Japan \\ Reviewed by: \\ Fumihiro Tanaka, University of \\ Occupational and Environmental \\ Health, Japan \\ Raja Flores, Mount Sinai Medical \\ Center, USA \\ *Correspondence: \\ Jan P. van Meerbeeck, Ghent \\ University Hospital, 11K12A, De \\ Pintelaan 185, 9000 Ghent, Belgium. \\ e-mail: jan.vanmeerbeeck@uzgent.be
}

Malignant pleural mesothelioma (MPM) is a rare, aggressive tumor with a poor prognosis. In view of the poor survival benefit from first-line chemotherapy and the lack of subsequent effective treatment options, there is a strong need for the development of more effective treatment approaches for patients with MPM. This review will provide a comprehensive state of the art of new investigational approaches for mesothelioma. In an introductory section, the etiology, epidemiology, natural history, and standard of care treatment for MPM will be discussed. This review provide an update of the major clinical trials that impact mesothelioma treatment, discuss the impact of novel therapeutics, and provide perspective on where the clinical research in mesothelioma is moving. The evidence was collected by a systematic analysis of the literature (2000-2011) using the databases Medline (National Library of Medicine, USA), Embase (Elsevier, Netherlands), Cochrane Library (Great Britain), National Guideline Clearinghouse (USA), HTA Database (International Network of Agencies for HealthTechnology Assessment - INAHTA), NIH database (USA), International Pleural Mesothelioma Program -WHOLIS (WHO Database), with the following keywords and filters: mesothelioma, guidelines, treatment, surgery, chemotherapy, radiotherapy, review, investigational, drugs. Currently different targeted therapies and biologicals are under investigation for MPM. It is important that the molecular biologic research should first focus on mesothelioma-specific pathways and biomarkers in order to have more effective treatment options for this disease. The use of array technology will be certainly an implicit gain in the identification of new potential prognostic or biomarkers or important pathways in the MPM pathogenesis. Probably a central mesothelioma virtual tissue bank may contribute to the ultimate goal to identify druggable targets and to develop personalized treatment for the MPM patients.

Keywords: mesothelioma, chemotherapy, targeted therapy

\section{INTRODUCTION}

The etiology, epidemiology, diagnosis, prognosis, and management of MPM have recently been reviewed and guidelines have been issued (Stahel et al., 2009; Scherpereel et al., 2010). Malignant pleural mesothelioma (MPM) is a rare but aggressive neoplasm that arises from the mesothelial surfaces of the pleural cavity. MPM has a bad prognosis: median survival of untreated cases is 6-9 months with less than 5\% 5-year survivors. Essential prognostic factors associated with better outcome are earlier stage and epithelioid histologic type (UICC, 2006). Additional prognostic factors are the presence of symptoms, performance status, age, gender, and weight loss. The prognostic value of asbestos exposure is controversial.

\section{MANAGEMENT OF MPM: STANDARD OF CARE \\ Palliative radiotherapy}

The aim of palliative radiotherapy is pain relief and may be considered in cases of painful chest wall infiltration or nodules (Ung et al., 2006). Responses of over $60 \%$ have been seen, although the duration of response - a median of 2-3 months - is often disappointing. The optimum dose has not been shown and many of the series were small and retrospective. Palliative radiotherapy is more effective if bone erosion or subcutaneous masses are present and less for diffuse pain, dyspnoea, superior vena cava syndrome or for retreatment.

\section{Palliative surgery}

Debulking pleurectomy/decortication (P/D) can be defined as significant but incomplete macroscopic clearance of pleural tumor. The objective of the operation is to relieve an entrapped lung by removing the visceral tumor cortex. Removal of the parietal tumor cortex may relieve a restrictive ventilatory deficit and reduce chest wall pain. The operative procedure needs to be further standardized and may be performed by either open thoracotomy, but the closed video assisted thoracoscopic surgery (VATS) is preferred. There are series of retrospective studies which provide low grade evidence for P/D (Waller et al., 1995; Soysal et al., 1997; MartinUcar et al., 2001; Halstead et al., 2005; Muirhead and O'Rourke, 2007; Nakas et al., 2008).

\section{Palliative chemotherapy}

Two international randomized studies (Vogelzang et al., 2003; Van Meerbeeck et al., 2005) suggested that combination chemotherapy including cisplatin and an antifolate, either pemetrexed or raltitrexed, increases survival compared to single agent cisplatin. The median survival observed in both studies showed an improvement of 2.6-2.8 months for the combination arm. Based on these two randomized phase III trials, it is now generally accepted to treat patients with MPM with a combination of an antifolate with 
platinum. Other cisplatin-based combinations have also produced interesting response rates of $20-30 \%$ in phase II studies: etoposide, epirubicin, gemcitabine, vinorelbine, or methotrexate (Berghmans et al., 2003; Ellis et al., 2006). The combination of carboplatin with pemetrexed shows outcome data similar to the ones obtained with cisplatin and pemetrexed (Ceresoli et al., 2008; Santoro et al., 2008). Few things we do not really know about cisplatin/pemetrexed include: when to start therapy, when to stop (maintenance?) and the role of the predictive markers TS and ERCC-1. In second line, no randomized trial has yet demonstrated any benefit in overall survival or quality of life. In the last two decades, only seven phase II studies (Harvey et al., 1984; Sorensen et al., 1985, 2007; Giaccone et al., 2002a; Porta et al., 2005; Fennell et al., 2007; Zucali et al., 2008) have addressed this question but failed to come to any recommendation. Some promising activity was noted with pemetrexed alone (Sorensen et al., 2007) and a combination of cisplatin, irinotecan, and mitomycin (Fennell et al., 2007). In a phase III study, patients with progressive disease were randomized to best supportive care (BSC) or second line pemetrexed single agent (Jassem et al., 2008). Time to progression was significantly longer in the pemetrexed arm but there was no improvement in overall survival. This might be due to significantly more patients in the BSC arm receiving post discontinuation chemotherapy with pemetrexed compared with patients randomized in the pemetrexed arm. In the case of recurrent disease it is recommended to include patients in clinical studies. Patients showing an objective and symptomatic response can be rechallenged with pemetrexed.

\section{Radical treatment}

1. Radiation therapy to the full hemithorax is limited by critical organs such as the lung, the liver and heart most particularly, but also the spinal cord and the esophagus. Therefore it is difficult to administer a total dose more than 54 Gy to such a large volume. Therefore, sophisticated treatment techniques, oriented by surgeon's and pathologist's findings, are needed (Maasilta, 1991; Senan, 2003). Radical radiotherapy has never been compared to chemotherapy or surgery or to BSC (as part of combination therapy) in a prospective, randomized trial and no data exist supporting one or the other treatment (Chapman et al., 2006).

2. Radical surgery may be defined as an attempt to remove all macroscopic tumor from the hemithorax. These objectives are usually achieved by extrapleural pneumonectomy (EPP) with an en bloc resection of lung, visceral and parietal pleura, and ipsilateral hemi-pericardium and hemi-diaphragm, followed by pericardial and diaphragmatic reconstruction with prosthetic material (usually Gore-Tex ${ }^{\mathrm{TM}}$ ). Operative mortality has fallen to an acceptable level of around 5\% in experienced centers, but morbidity remains high at around 50\% (Sugarbaker et al., 2004; Opitz et al., 2006). Older literature indicates that surgery alone for MPM is not curative since no oncological resection margins can be obtained. The pleural lining, especially on the pericardium and mediastinum cannot be resected with a 1 to 2-cm margin and therefore all surgical procedures are considered R1 resections (Sugarbaker, 2006) and high local recurrence rates are the rule (Baldini et al., 1997) and this observation is therefore the rationale for combined modality therapy.
3. Postoperative radiotherapy (PORT) with 54 Gray (Gy) to the hemithorax after EPP resulted in a local recurrence rate of $13 \%$ and a $4 \%$ local-only recurrence rate (Rusch et al., 2001). Preliminary results of intensity-modulated radiotherapy (IMRT) in the adjuvant setting after EPP seemed particularly promising as they could provide good local control and protect organs at risk such as heart or liver (Ahamed et al., 2003). However, severe pulmonary toxicity has been reported in recent studies so that it should not be recommended outside of clinical trials (Allen et al., 2006; Rice et al., 2007).

4. The only published long-term survivors among resected mesothelioma patients have undergone radical surgery (EPP) as part of a combined modality treatment including postoperative chemotherapy with or without PORT (Sugarbaker et al., 1999; Flores et al., 2006). The preference for neo-adjuvant chemotherapy is justified by its better compliance, lower rate of surgical morbidity, high rate of objective response, good rate of radical resections and the possibility to select the optimal patients to be submitted to surgery. This approach was explored first in a number of single institutional phase II studies with promising results (Weder et al., 2004; De Perrot et al., 2009). A number of multicentre prospective phase II trials exploring the feasibility of a multimodality approach in highly selected patients, combining neo-adjuvant chemotherapy, followed by EPP and PORT have demonstrated a similar median survival of 17-20 months (Table 1; Weder et al., 2007; Krug et al., 2009; Van Schil et al., 2010). At least 2 more multicentre phase II trials addressing the same issues are on-going.

\section{INVESTIGATIONAL DRUG APPROACHES NEW ANTIFOLATES, PLATINUM ANALOGS, AND NEW THIRD GENERATION CYTOTOXIC AGENTS}

The cytotoxic activity of antifolates is mainly due to their ability to inhibit several different folate-dependent enzymes involved in DNA synthesis. The key enzyme in the folate metabolism of MPM is thymidylate synthase (TS). Low TS protein levels are predictive of improved overall survival in pemetrexed treated patiens with MPM (Righi et al., 2010). Glycinamide ribonucleotide formyl transferase (GARFT) and dihydrofolate reductase (DHFR) might also be of importance. The most widely used antifolate in the treatment of MPM is Pemetrexed. Pemetrexed is a third generation antifolate and primarily an inhibitor of TS with also potent, but lesser, inhibition of GARFT and DHFR. It has a substrate specific high-affinity transport route in mesothelioma cell lines, favoring its use in MPM (Wang et al., 2002).

Novel antifolates include nolatrexed, an oral specific TS inhibitor that was developed using protein structure-based drug design, primarily for the treatment of hepatocellular carcinoma. Only one patient with MPM was included in a phase I trial and its development was halted after a negative phase III trial in hepatocellular carcinoma (Hughes et al., 1999; Gish et al., 2007). New DHFR inhibitors such as pralatrexate, talotrexin, and previtrexed have also been developed, but at the moment only pralatrexate has been tested in MPM. In a phase II study it showed no activity as an single agent (Krug et al., 2007). AG 2037 is a GARFT inhibitor being evaluated for its activity in NSCLC and colorectal cancer (Webber et al., 1996). No trials have been conducted for its effect in MPM. 
Table 1 | Prospective multicentre phase II trials of radical multimodality treatment in early stage mesothelioma.

\begin{tabular}{llll}
\hline Variable & SAKK-trial (Weder et al., 2007) & US-trial (Krug et al., 2009) & EORTC trial (Van Schil et al., 2010) \\
\hline N/n institutions & $61 / 6$ & $77 / 9$ & $59 / 11$ \\
Induction regimen & Cis-gem $\times 3$ & Cis-pem $\times 4$ & Cis-pem $\times 3$ \\
Compliance to induction chemotherapy & $95 \%$ & $83 \%$ & $93 \%$ \\
EPP & $45(74 \%)$ & $54(70 \%)$ & $42(74 \%)$ \\
Operative mortality & $2.2 \%$ & $7 \%$ & $6.5 \%$ \\
PORT completed & $36(59 \%)$ & $40(52 \%)$ & $37(65 \%)$ \\
Median OS (ITT; range) & $19.8 \mathrm{~m}$ & $16.8 \mathrm{~m}$ & $18.4 \mathrm{~m}$ \\
Median OS (PP) & $23 \mathrm{~m}$ & $29.1 \mathrm{~m}$ & $\mathrm{NA}$ \\
Local relapse (\% PP) & $\mathrm{NS}$ & $11(28 \%)$ & $6(16 \%)$ \\
Median PFS (ITT) & $13.5 \mathrm{~m}$ & $10.1 \mathrm{~m}$ & $13.9 \mathrm{~m}$ \\
Median overall treatment time (days; range) & $\mathrm{NS}$ & $\mathrm{NS}$ & 184
\end{tabular}

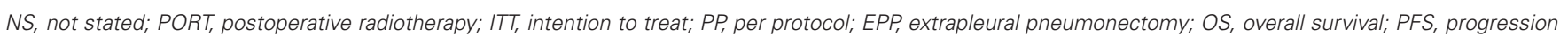
free survival.

Cisplatin and carboplatin are effective in MPM both as single agents and as a component of combination chemotherapy. The efficacy of these platinum analogs is limited by several (intrinsic and acquired) mechanisms of resistance, including impaired cellular uptake, intracellular inactivation by thiols and enhanced DNA repair. New platinum analogs have been developed to overcome this platinum resistance, though no new small molecule platinum drug has entered clinical trials since 1999. AMD 473 is a platinum analog that is less susceptible to detoxification by intracellular thiols. AMD 473 demonstrated no activity in phase II trials with a total of 41 previously treated mesothelioma patients (Giaccone et al., 2002b). Other platinum analogs including picoplatin, satraplatin, lobaplatin, and nedaplatin showed lower levels of toxicity in phase I and II trials but have failed to demonstrate superior efficacy in MPM compared to the classical platinum analogs cisplatin and carboplatin (Kelland, 2007).

Vinca alkaloids have activity in MPM. Vinorelbine is active in first and second line treatment.

In a phase II trial the efficacy and activity of a regimen of carboplatin together with vinorelbine administered i.v. and orally was evaluated. The regimen was easy to administer and generally well tolerated without any toxic deaths in spite of the poor prognostic patient population and the median survival was in excess of 9 months. The regimen was considered equally active as the combination of cisplatin and vinorelbine (Sørensen et al., 2007).

In vitro and in vivo, resistance to the novel vinca alkaloid vinflunine, develops less readily than to vinorelbine. In an phase II trial vinflunine achieved a response rate of $13.8 \%$ and a median survival of 10.8 months (Talbot et al., 2007).

Microtubule-stabilizing agents such as the taxanes have shown only modest activity in MPM. The epothilones, a novel class of microtubule-stabilizing agents, are being tested in breast cancer, melanoma, and renal cell carcinoma. In light of the limited effect of the taxanes, they have not been tested in MPM patients in phase II or III trials.

Amrubicin combines anthracycline activity and potent topoisomerase II inhibition.
In phase II trials of small cell lung cancer, it showed superior response rates compared to the topoisomerase I inhibitor topotecan (Jotte et al., 2010). Anthracyclines have shown activity in MPM, making amrubicin a promising future candidate for the treatment of MPM.

Trabectedin (also known as ecteinascidin 743 or ET-743) is a tetrahydroisoquinoline alkaloid isolated from a marine tunicate growing in mangrove roots. It is effective in metastatic soft tissue sarcoma. A Phase II Study is completed, but the data have not yet been published (Anonymous, n.d.f).

Alanosine (also called SDX-102) is an antimetabolite. It failed to show objective responses in a phase II trial including 16 patients with MPM (Kindler et al., 2009).

Most cancer cells are dependent on the G2 checkpoint to survive with DNA damage. The stable peptide CBP501 shows selective G2 checkpoint abrogation, with activity in various tumor models, alone and combined with DNA damaging agents. A phase I/II trial of CPB501 combined with cisplatin and pemetrexed is recruiting patients. The phase II part will evaluate full-dose cisplatin and pemetrexed combined with CBP501 (at the maximum tolerated dose, MTD determined in the phase I part) in previously untreated, unresectable MPM patients (Anonymous, n.d. e).

\section{BIOLOGICALS AND TARGETED THERAPIES}

Recent pharmaceutical developments have focused on the identification and inhibition of molecular pathways involved in the growth and progression of MPM. A number of novel agents have been or are being evaluated, including drugs targeted against the epidermal growth factor, platelet derived growth factor, vascular endothelial growth factor, src kinase, histone deacetylase, the proteosome and mesothelin (Table 2).

The epidermal growth factor receptor (EGFR) is a receptor tyrosine kinase that is over-expressed in a variety of malignancies. Signaling through EGFR is associated with inhibition of apoptosis, with resistance to chemotherapy, and metastases. EGFR was observed to be over-expressed on immunohistochemistry (IHC) in a majority of epithelioid mesothelioma specimens (Dazzi et al., 1990). Based on these data, the CALGB conducted a phase II trial that 
Table 2 | Targeted agents in MPM.

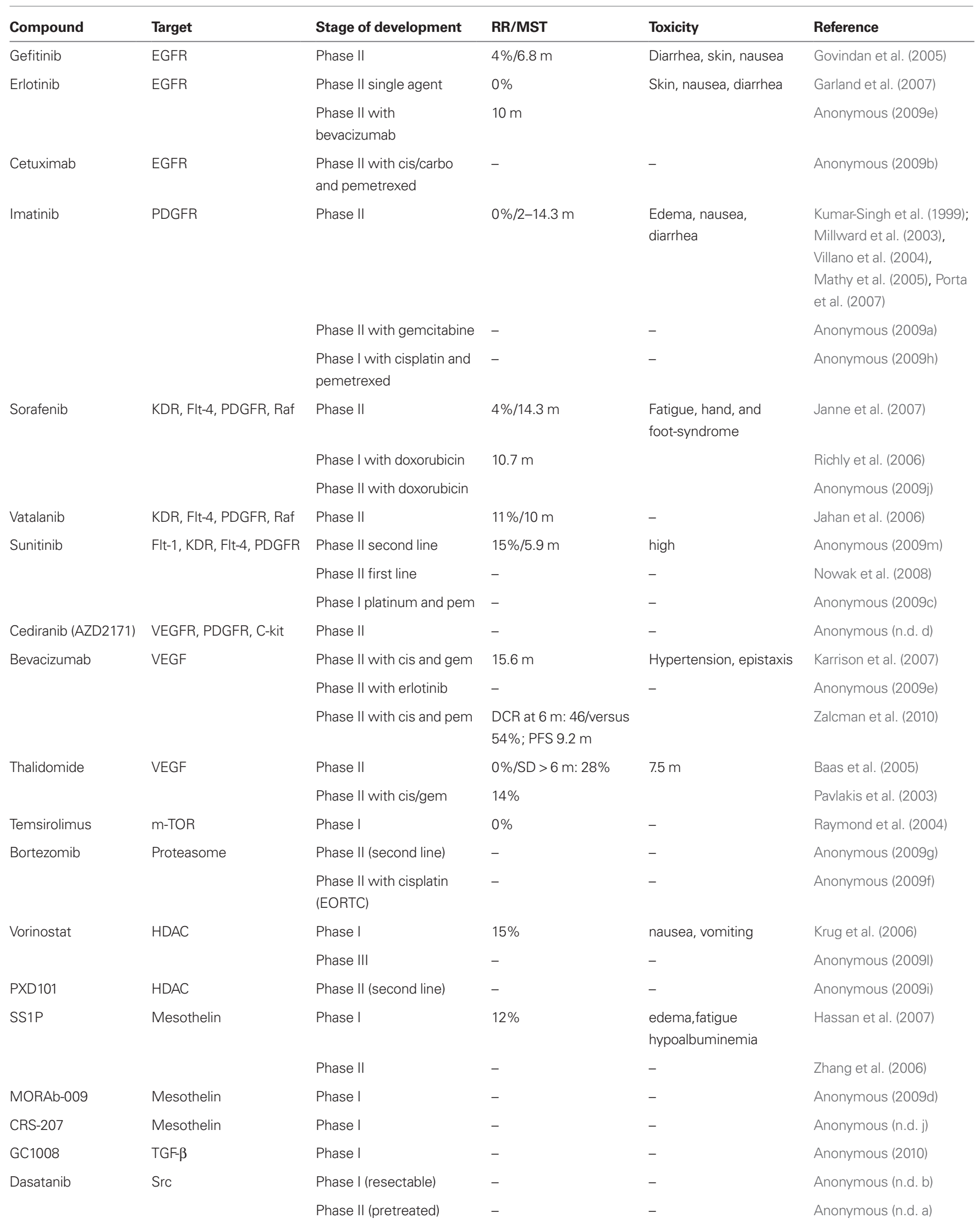


evaluated the role of gefitinib in the treatment of MPM (Govindan et al., 2005). No objective responses were reported and the regimen was not deemed suitable for further evaluation. Erlotinib, another EGFR inhibitor, was also evaluated in a phase II study for patients with MPM (Garland et al., 2007). No objective responses were seen despite a high rate of patients with EGFR-expressing tumors in the study. A possible explanation of absence of significant benefit from using EGFR-TKIs could be due to the absence of activating somatic mutation in EGFR-TKI domain that is strongly predictive of response to EGFR-TKIs (Cortese et al., 2006). Cetuximab, a monoclonal antibody against the EGF receptor is currently investigated in a phase II study in combination with platinum and pemetrexed (Anonymous, 2009b). Another Her-family member, ErbB-2 or Her2/neu is expressed in $97 \%$ of mesothelioma specimens on IHC. However, the ErbB-2 gene does not appear to be amplified and data from breast cancer studies suggest that specific ErbB-2 inhibitors may not be effective in the absence of amplification.

Findings derived from clinical and preclinical studies suggest that angiogenesis may be an important process in the pathogenesis of MPM. VEGFs and their receptors are over-expressed in MPM tissue, cell lines, pleural effusion and non-malignant mesothelial specimens and effusions (Kumar-Singh et al., 1999; Strizzi et al., 2001). Circulating VEGF and high microvasculature density significantly correlate with worse prognosis (Edwards et al., 2001). Angiogenesis allows the formation of new blood vessel essential for tumor growth. The first findings that linked mesothelioma and angiogenesis were reported by Branchaud et al. (1989). Recent data suggest the existence of relationship between SV40 and VEGF in MPM. In mesothelial cell cultures SV40 positive the levels of VEGF were significantly higher. Mesothelial cell transfected with SV40 or only with SV40 Tag antigen releases great amount of VEGF proteins and mRNA that leads to cell line proliferation. The inactivation of VEGF signal transduction pathway abolished this proliferation. Ligand-receptor interaction induces the activation of the tyrosine kinase domain of the VEGFRs, which leads to the activation of intracellular signal transduction pathways, such as the Raf/MEK/ extracellular signal-regulated kinase (ERK) and the PI3K/AKT. VEGFR-1 regulates positively the angiogenesis and is thought to be important for endothelial cell migration and differentiation. VEGFR-2 mediates most downstream effects of VEGF-A, including vascular permeability, endothelial cell proliferation, invasion, migration, and survival. VEGFR-3 is involved in lymphangiogenesis, and its expression has been associated with the dissemination of tumor cells to regional lymph nodes. Proteins involved in regulating the angiogenic process have been implicated in the prognosis of MPM and can be indirectly assessed using immunohistochemistry and micro-vessel counting. Studies have indicated that increased micro-vessel density is associated with a poor outcome (Edwards et al., 2001).VEGF, the VEGF receptors (VEGFRs) flt-1 (VEGFR-1), KDR (VEGFR-2), and VEGFC and its cognate receptor VEGFR-3 have been shown to be co-expressed in MPM (Ohta et al., 1999; Strizzi et al., 2001). Both VEGF and VEGFC function as autocrine growth factors for the development of MPM.

A randomized phase II study was conducted in patients with advanced MPM to evaluate whether the addition of bevacizumab, a monoclonal antibody against VEGFR, can enhance the efficacy of chemotherapy (Karrison et al., 2007). Patients were treated with cisplatin and gemcitabine with or without bevacizumab. The treatment was tolerated well without any major toxicity. Nevertheless, there was no improved outcome with the addition of bevacizumab. The median progression free survival with and without the addition of bevacizumab, were 6.9 and 6.0 months, respectively. Although the median overall survival was numerically superior for bevacizumab + chemotherapy (15.6 versus 14.7 months), this difference was not statistically significant. An exploratory subset analysis noted improved survival with bevacizumab-chemotherapy regimen in patients with low circulating levels of VEGF. The multicenter, randomized phase II-III trial (MAPS) of cisplatin-pemetrexed with or without bevacizumab showed a DCR at 6 months of $46 \%$ versus $54 \%$ for the bevacizumab arm. A promising PFS of 9.2 months was shown. Biomarker studies are on-going (Zalcman et al., 2010). Based on these results the IDMC recommended a phase III trial. An ongoing phase II study is addressing the activity of bevacizumab added to erlotinib in second line (Anonymous, 2009e).

Several small molecule inhibitors of the VEGF receptor tyrosine kinase have been tested in phase II studies. The multikinase inhibitor sorafenib inhibits the Ras/Raf/MEK/ERK and p38 signaling pathways, VEGFR-2 and VEGFR-3, and members of the PDGF receptor family, PDGFR $\beta$ and c-Kit. Sorafenib was evaluated as monotherapy for recurrent MPM in a phase II study by the CALGB (Janne et al., 2007). Treatment was tolerated well, but the response rate of $4 \%$ did not meet the criteria for further evaluation of this agent as monotherapy. In a phase I study, one patient with MPM reported a partial response when sorafenib was combined with doxorubicin (Richly et al., 2006). This combination is currently under evaluation in a phase II study in MPM (Anonymous, 2009j).

PTK 787 (vatalanib), an aminophenazone derivative, is an inhibitor of all known VEGFRs and, at higher concentrations, of PDGFR and c-kit. In a Phase II study, the efficacy of vatalanib was studied and correlated the response to treatment with circulating serum levels of VEGF, PDGF, and VEGF in chemonaive patients with MPM. RR was $11 \%$, median OS 10 months, and PFS 4.1 months (Jahan et al., 2006). However, the study did not meet the prespecified end point of 3-month PFS rate. No correlation was observed between baseline VEGF or PDGF levels and response, PFS, or survival.

Sunitinib a tyrosine kinase inhibitor that acts on several targets, such as VEGFRs, PDGFR $\beta$, and c-Kit is under evaluation in untreated MPM patients in a phase II study (Anonymous, 2009m) and has been tested in a Phase II study on patients who failed after a platinum plus pemetrexed regimen. A partial response in $15 \%$ of patients and stable disease in 55\% of them was seen. The median OS was 5.9 months and the median TTP of 3.5 months. Moreover, the role of $\left[{ }^{18} \mathrm{~F}\right]$ fluorodeoxyglucose positron emission tomography was also evaluated. A metabolic response was observed in $30 \%$ of patients without talc pleurodesis. Final results of this trial has been presented at ASCO 2010 and the authors concluded that activity was modest and toxicity high (Nowak et al., 2008). Sunitinib is under research in a phase I study in association with pemetrexed/cisplatin and pemetrexed/carboplatin and pemetrexed (Anonymous, 2009c).

Other VEGF tyrosine kinase inhibitors that are currently under evaluation include cediranib and pazopanib. AZD2171 (cediranib maleate), an indole-ether quinazoline derivative that acts with all three VEGFRs, with PDGFR and c-kit, is being evaluated in a Phase II study (Anonymous, n.d. d). 
Thalidomide, a broadly targeted agent, inhibits angiogenesis mediated by VEGF, basic fibroblast growth factor (FGF) and TGF$\alpha$. A Phase II study evaluated the efficacy of thalidomide in 40 patients who have mesothelioma, of whom $50 \%$ had received previous chemotherapy. Disease stabilization for longer than 6 months was reported in $27.5 \%$ of the patients (Baas et al., 2005). Pavlakis et al. (2003) evaluated thalidomide alone or in combination with gemcitabine/cisplatin in two parallel non-randomized phase II studies. Single agent thalidomide was administered to 22 patients who were not considered suitable for chemotherapy nor progressed during treatment with antineoplastic drugs, whereas gemcitabine plus cisplatin was given with thalidomide to 16 chemotherapy-naive patients. Disease stabilization for longer than 6 months was observed in $25 \%$ of the patients who received single agent thalidomide, while in the combination arm, a partial response rate of $14 \%$ was reported, and $32 \%$ of these patients achieved disease stabilization for longer than 6 months. Moreover, a non-significant trend suggested that higher baseline levels of VEGF correlated with a shorter survival in both arms. However, when administered as consolidation following first-line platinum-antifolate based chemotherapy, thalidomide did not improve outcome when compared to placebo (Baas et al., 2011).

Imatinib is a highly selective inhibitor of the bcr/abl mutated tyrosine kinase, as well as of both c-kit and PDGFRs. Several Phase II studies have been conducted with imatinib mesylate in MPM refractory to chemotherapy or chemonaive patients, but negative results were reported (Kumar-Singh et al., 1999; Millward et al., 2003; Villano et al., 2004; Mathy et al., 2005; Porta et al., 2007). In vitro and in vivo experiments demonstrated that STI-571 can cause MPM cell apoptosis and death through inhibition of the AKT/PI3K pathway and that it can also enhances MPM sensitivity to gemcitabine or pemetrexed (Bertino et al., 2007). Patients with MPM are currently being enrolled in a Phase I study of imatinib combined with cisplatin and pemetrexed (Anonymous, 2009h) and in a phase II study in association with gemcitabine to evaluate the efficacy of these compounds (Anonymous, 2009a).

Rapamycin, a natural macrolide approved as immunosuppressor, was found to exert anti-proliferative effects by inhibition of serine/ threonine kinase, which in mammals is called mammalian target of rapamycin (m-TOR). Synthetic derivatives or "rapalogs" have been developed to improve the pharmacological properties of rapamycin: everolimus, temsirolimus, and deforolimus. Temsirolimus was evaluated in a phase I study of dose-escalation and no tumor response in patients with MPM was observed (Raymond et al., 2004).

Histone deacetylase (HDAC) inhibitors are novel anticancer agents that act by a variety of mechanisms. Histones are the coreproteins in the center of the DNA double helix. The histone proteins exist in either a non-acetylated transcriptional inactive configuration or an acetylated state that is open to gene transcription. The dynamic equilibrium between the acetylated and non-acetylated forms is mediated by histone acetyltransferase and HDAC (Marks et al., 2001). Agents that inhibit HDAC have recently demonstrated promising anticancer activity in early phase clinical trials. Vorinostat is a small molecule inhibitor of HDAC that is approved by the FDA for the treatment of advanced, relapsed, or refractory cutaneous T-cell lymphoma. In addition to its inhibitory effect on HDAC, vorinostat also acetylates several key cell signaling proteins that play a role in regulating normal cell differentiation, apoptosis, and proliferation. Therefore, both histone and non-histone proteinmediated effects of HDAC inhibitors are thought to be responsible for their anticancer effects (Deroanne et al., 2002). Initial studies of vorinostat have demonstrated objective responses in patients with MPM. In the initial phase I studies with the oral formulation of vorinostat, 13 patients with advanced MPM were included (Krug et al., 2006). Twelve out of these patients had received prior systemic chemotherapy for MPM. Two objective partial responses were reported and the treatment regimen was tolerated well. These data form the basis for a large randomized clinical trial to compare vorinostat to placebo in pretreated patients. The primary end point is overall survival (Anonymous, 2009l). The mechanistic aspects of the efficacy noted with vorinostat in MPM are unclear. Because inhibitors of thymidylate synthase (TS) have demonstrated activity in MPM, it is conceivable that repression of TS and cytidine triphosphate synthetase by HDAC inhibitors could play a role. Another mechanism may be the induction of apoptosis, which has been demonstrated with preclinical studies of sodium butyrate, a HDAC inhibitor, in mesothelioma cell lines. HDAC inhibitors have also been shown to block angiogenic signaling by inhibiting VEGFinduced expression of VEGF receptors. Another HDAC inhibitor, belinostat, is being evaluated in a Phase II study as a second line therapy (Anonymous, 2009i).

The proteasome inhibitor bortezomib inhibits nuclear factorkappa $\mathrm{B}$ and up-regulates pro-apoptotic $\mathrm{BH} 3$ proteins (Fennell et al., 2008). Proteasome inhibition induces apoptosis of mesothelioma cells in vivo and in vitro (Gordon et al., 2007; Sartore-Bianchi et al., 2007). On the basis of promising preclinical data, two phase II trials of bortezomib have been initiated in Europe. One trial is exploring single agent activity in the second line setting and in patients with a performance status of 2 in the first-line setting (Anonymous, 2009g). The second trial, conducted by the EORTC, has explored this agent in combination with cisplatin in the firstline setting (Anonymous, 2009f).

Other angiogenic growth factors expressed in this disease include transforming growth factor $\beta$, FGF1, FGF2, thrombospondin 1, methionine amino-peptidases, interleukin (IL)-6 and IL-8. High levels of VEGF and FGF2 or co-expression of TGF $\beta$, VEGF, FGF1, and FGF2 have been found to be associated with a poor outcome. MPM exhibits high levels of expression of the surrogate marker of hypoxia, hypoxia-inducible factor $1 \alpha$ (Klabatsa et al., 2006).

Blockade of TGF- $\beta$ is an new approach for mesothelioma. GC1008 is a human IgG4 kappa monoclonal antibody capable of neutralizing all mammalian isoforms of TGF- $\beta$ (i.e., $\beta 1, \beta 2$, and $\beta 3)$. GC1008 is a high-affinity antibody with dissociation constants (Kds) of 1.8, 2.8, and 1.4 nM for TGF1, 2, and 3, respectively. The anti-TGF Monoclonal Antibody GC1008 is currently investigated in relapsed MPM (Anonymous, 2010).

Dasatinib, a Src inhibitor, is currently evaluated in a phase II trial in pretreated patients and in another trial in patients with resectable mesothelioma (Anonymous, 2010; Anonymous n.d. a).

\section{MESOTHELIN TARGETED IMMUNOTHERAPY}

Mesothelin is a differentiation antigen whose expression in normal human tissues is limited to mesothelial cells lining the pleura, pericardium, and peritoneum. However, mesothelin is highly expressed 
in several human cancers, including virtually all mesotheliomas and pancreatic adenocarcinomas, and approximately $70 \%$ of ovarian cancers and $50 \%$ of lung adenocarcinomas. Mesothelin gene expression in human cancers has been studied using serial analysis of gene expression (SAGE) tag analysis. High mNA expression of mesothelin is found in mesothelioma, lung, ovarian, and pancreatic adenocarcinomas. In addition, immunohistochemistry has helped delineate the frequency and pattern of mesothelin protein expression in these tumors. These studies have been greatly facilitated by the commercial availability of a monoclonal antibody (mAb) 5B2 (Novocastra, Newcastle-on-Tyne, UK) that can detect mesothelin expression in paraffin embedded tissues. Mesothelin is highly expressed in epithelial malignant mesothelioma (Figure 1). In the original study by Chang et al. (1992), mesothelin expression was evaluated by mAb-K1 using frozen section tissues of patients with malignant mesothelioma. Out of the 23 pleural mesothelioma samples analyzed all 15 epithelial mesothelioma samples had mesothelin expression, while 4 sarcomatous mesotheliomas were negative. In the four samples with biphasic mesothelioma, only the epithelial component stained for mesothelin. Mesothelin expression in paraffin embedded mesothelioma tissue samples was studied by Ordonez (2003) using mAb 5B2. Out of the 55 mesothelioma specimens ( 44 epithelioid, three biphasic, and eight sarcomatoid) studied, mesothelin reactivity was noted in all epithelioid mesotheliomas and the epithelial component of biphasic mesotheliomas and none of the sarcomatous mesotheliomas expressed mesothelin. Although mesothelin is not a specific marker for mesothelioma a negative mesothelin immunostain strongly argues against the diagnosis of epithelioid mesothelioma (Ordanez, 2007). To determine whether a spontaneous humoral B-cell response to mesothelin is present in patients with mesothelin expressing cancers Ho et al. (2005) used a sensitive enzyme-linked immunosorbent assay (ELISA) to detect mesothelin-specific IgG antibodies in serum of patients with advanced mesothelioma and ovarian cancer. Elevated levels of mesothelin-specific antibodies were detected in the sera of 27 of $69(39 \%)$ patients with mesothelioma and 10 of $24(42 \%)$

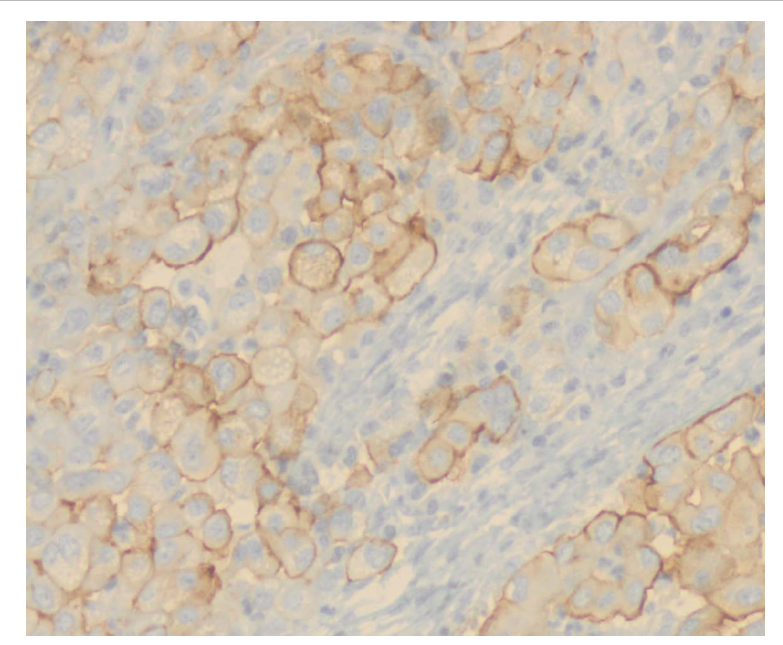

FIGURE 1 | Mesothelin expression detected by IHC in tissue specimens of patients with MPM (×250). patients with epithelial ovarian cancer when compared with a normal control population. Mesothelin-specific antibodies were present at a higher frequency in patients whose tumors had strong mesothelin expression by immunohistochemistry. These results suggest that the immunogenicity of mesothelin is associated with its high expression on the tumor cells and serologic recognition of mesothelin is cancer related. The presence of a mesothelin-specific B-cell response in a significant proportion of patients with mesothelin expressing tumors supports on-going efforts to use mesothelin as a therapeutic cancer vaccine. Several agents with activity in preclinical models are being developed to target mesothelin: a recombinant immunotoxin (SS1P), a humanized monoclonal antibody (MORab-009) and an attenuated Listeria vector that encodes human mesothelin (CRS-207).

SS1P is a recombinant immunotoxin consisting of an anti-mesothelin Fv linked to a truncated Pseudomonas exotoxin that mediates cell killing (Chowdhury et al., 1998; Chowdhury and Pastan, 1999). After binding to mesothelin, the immunotoxin is internalized via clathrin coated pits, undergoes processing in the endocytic compartment and the immunotoxin fragment containing the ADPribosylation domain is transported to the endoplasmic reticulum and then translocated to the cytosol where it inhibits elongation factor-2 leading to inhibition of protein synthesis and ultimately cell death (Hassan et al., 2007). Recent studies have looked at the anti-tumor activity of SS1P in combination with radiation therapy or chemotherapy. Athymic nude mice bearing A431/K5 mesothelin expressing tumors were treated with radiation alone, SS1P alone or the two agents in combination (Chowdhury et al., 1998). The results of this study showed that mice treated with low-dose radiation and SS1P or high-dose radiation and SS1P had a statistically significant prolongation in time to tumor doubling or tripling compared with control, SS1P or radiation alone treated mice. Since radiation treatment increased the cell surface expression of mesothelin, it is possible that the increased anti-tumor activity of SS1P in combination with radiation is partly due to enhanced mesothelin expression, making the cells more sensitive to SS1P treatment. Given the nonoverlapping toxicities and different modes of action of SS1P and chemotherapeutic agents, combining them could potentially result in increased anti-tumor activity in patients.

Two Phase I studies of SS1P have just been completed. These studies which were designed to test the safety, MTD, and pharmacokinetics of SS1P used two different strategies for SS1P administration. In one study SS1P was administered as an intravenous bolus infusion over $30 \mathrm{~min}$ (SS1P bolus infusion study) while as in the other study SS1P was given as a continuous i.v. infusion over 10 days (SS1P continuous infusion study). Most common toxicities were similar for both the bolus infusion and continuous infusion including hypoalbuminemia, weight gain, edema, and fatigue. Of the 33 evaluable patients treated, four had minor responses, 19 had stable disease (including two with resolution of ascites and died after 5 years after the therapy), while 10 had progressive disease (Hassan et al., 2007). Based on this study and in previously reported synergistic effects of SSP1 in combination with chemotherapy (Zhang et al., 2006), a phase II study is planned.

MORAb-009 is a high-affinity chimeric (mouse/human) monoclonal IgG1/ $\kappa$ with high-affinity and specificity for mesothelin. The heavy and light chain variable regions of mouse anti-mesothelin 
scFv (obtained by panning on mesothelin-positive cells a phage display library made from splenic mRNA of a mouse immunized with mesothelin cDNA) were grafted in frame with human IgG1 and $\kappa$ constant regions. Since MORAb-009 is a chimeric antibody containing only the mouse sequences that recognize human mesothelin, it should be less immunogenic and allow repeated administration to patients. Laboratory studies show that MORAb-009 kills mesothelin expressing cell lines via antibody dependent cellular cytoxicity (ADCC) and in addition it inhibits the binding of mesothelin to CA-125. Based on these preclinical studies a Phase I clinical trial of MORAb-009 has been completed (Anonymous, 2009d).

The rationale for mesothelin as a tumor vaccine is based on studies showing that mesothelin can elicit a strong CD8+ T-cell response in patients (Thomas et al., 2004). One of the mesothelin cancer vaccines in advanced stages of clinical development is CRS-207 ( $L m \Delta a c t A / \Delta i n l B / h M e s o)$. This vaccine utilizes a liveattenuated strain of the bacterium Listeria monocytogenes $(\mathrm{Lm})$, a facultative intracellular bacterium, as the vector 40 (Brockstedt et al., 2004). The engineered vector CRS-100, has deletions of the two genes that encode the virulence determinants actA and internalin B (inlB), which results in a greater than 1000-fold decrease in virulence compared to the wild type $\mathrm{Lm}$. CRS-207 is a live-attenuated $L m$ vaccine strain based on CRS-100 that encodes human mesothelin. Preclinical studies show that CRS-207 elicits human mesothelin-specific CD4+/CD8+ immunity in mice and in cynomolgus monkeys and exhibits therapeutic efficacy in tumor bearing mice (Giedlin et al., 2007). A Phase I clinical trial of CRS-207 for the treatment of patients with mesothelin expressing cancers is on-going (Anonymous, n.d. j). The utility of mesothelin as a tumor vaccine came from a clinical trial conducted by Jaffe and colleagues that involved vaccination of pancreatic cancer patients with GM-CSF transduced pancreatic cancer cell lines (Jaffee et al., 2001). Out of the 14 patients treated on this study three developed a post-vaccination delayed-type hypersensitivity (DTH) response to the autologous tumor, that was associated with prolonged survival (Yokokawa et al., 2005). In another vaccine study, T-cell lines derived from the native or the agonist mesothelin epitope were shown to lyse mesothelin expressing and HLA-2 positive pancreatic cancer, ovarian cancer, and mesothelioma cell lines (Yokokawa et al., 2005). All these studies support the potential utility of mesothelin in peptide and/or vector-mediated immunotherapy protocols for the treatment of cancers that highly express mesothelin.

\section{VACCINE APPROACHES}

Vaccine approaches are also under investigation for the treatment of MPM. Wilms tumor associated gene (WT)-1 is a transcription factor expressed in tissues of mesodermal origin during embryogenesis. Up-regulation of WT-1 has been linked with tumourigenesis of various malignancies including mesothelioma and is an attractive target for immunotherapy (May et al., 2007). Therefore, WT-1 peptide epitopes that stimulate T-cell immunity are currently under evaluation for the treatment of mesothelioma. Preliminary results from on-going studies have documented the safety of this vaccine. Interesting preliminary results were observed after administration of Mycobacterium vaccae in a limited number of patients. This needs to be confirmed before further exploring this treatment. A randomized study of adjuvant WT-1 analog peptide vaccine in patients with MPM after completion of combined modality therapy is on-going (Anonymous, n.d.h). Mesothelin as tumor vaccine has been described in the previous section.

\section{DENDRITIC CELL BASED IMMUNOTHERAPY}

Immunotherapy is a promising approach in the treatment of cancer. It tries to harness the potency and specificity of the immune system to attack cancer cells. The aim is a non-toxic treatment with minor side-effects and a long-lasting immunological memory. One approach of immunotherapy uses dendritic cells (DC) to present tumor-associated antigens (TAA) and thereby generate tumorspecific immunity (Steinman and Dhodapkar, 2001; Banchereau and Palucka, 2005) DC are extremely potent antigen-presenting cells specialized for inducing activation and proliferation of CD8+ cytotoxic T lymphocytes (CTL) and helper CD4+ lymphocytes. Hegmans et al. (2005) demonstrated in a murine model that immunotherapy, using pulsed DC, may emerge as a powerful tool to control mesothelioma outgrowth. They showed that mesothelioma is infiltrated by immune effector cells but also contains cytokines and regulatory $\mathrm{T}$-cells that suppress an efficient immune response. Immunotherapy of mesothelioma might be more effective when combined with drugs that eliminate or control regulatory T-cells (Hegmans et al., 2006). They have also demonstrated that the efficacy of immunotherapy was dependent on the tumor load. The most beneficial effects were established at early stages of tumor development. This is in agreement with the current knowledge of the effect of immunotherapy in other tumor types (Cranmer et al., 2004). On the basis of these preclinical animal studies, a clinical trial in which autologous tumor lysate-pulsed DC were administered intra-dermally and intravenously in mesothelioma patients after cyto-reductive therapy with chemotherapy is now completed. Patients received $50 \times 10^{6}$ mature DC pulsed with tumor lysate and keyhole limpet hemocyanin (KLH) every 2 weeks for a total of three injections. The administration of DCs loaded with autologous tumor cell lysate to patients was safe. Local skin reactions were seen at the site of the intradermal injection suggesting that some form of immunity was induced. There was no clinical or radiological evidence of any autoimmunity. Distinct immunological responses to the surrogate marker KLH were induced by the vaccinations, both in vitro as in vivo. Importantly, anti-tumor cytotoxicity activity against autologous tumor cells was measured in the blood of patients. An increase in systemic CTL activity was seen in a subset of treated patients (4 out of 6). Multiple vaccinations were necessary as the increase in CTL activity was seen only after 3 vaccinations for most of the patients in this assay. DC loaded with autologous tumor cell lysate administrated to patients was considered safe and feasible and no adverse effects were observed. Anti-tumor immune responses were detected in a few patients with mesothelioma after DC-immunotherapy. Whether this has a beneficial effect in improving survival will be the subject in successive studies. Influencing the immunosuppressive cells (Tregs, M2 macrophages, and MDSC), cells abundantly present in the tumor environment, and their subsequent effect on DC-mediated antitumor responses, seems of critical importance for future clinical trials. Also other sources of antigens to pulse DC must be investigated to make DC-immunotherapy more accessible for larger numbers of patients to perform comparative studies (Figure 2). 


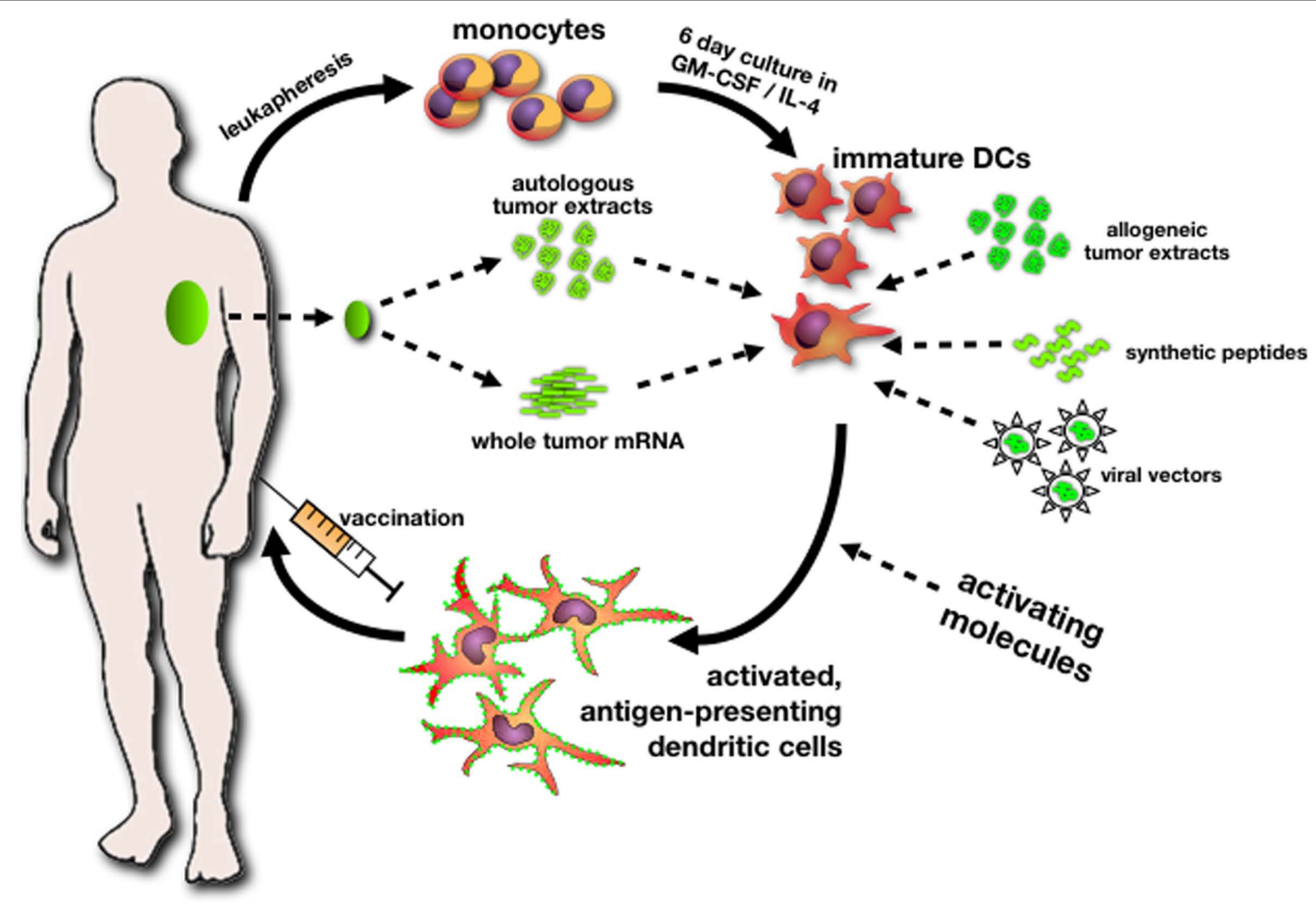

FIGURE 2 |A general workflow for the production of autologous dendritic cell vaccines for cancer immunotherapy. Monocytes, harvested from a leukapheresis, are differentiated in vitro under GMP-conditions into immature dendritic cells. The prototypical cytokines used for the generation of monocytederived DCs are GM-CSF and IL-4. Immature DCs can subsequently be loaded with tumor-derived antigens using different approaches: DCs can phagocytose proteins from autologous tumor lysate or be electroporated with tumor-derived
mRNA. When access to autologous tumor is too limiting, DCs can be loaded with allogeneic tumor proteins, peptides derived from putative tumor-associated antigens (TAAs), or transduced with viral vectors encoding TAAs. A crucial final step in the whole process is the activation/maturation of DCs, typically using Toll-like receptor ligands and/or a cocktail of activating cytokines. The resulting activated, tumor antigen-presenting DCs constitute the vaccine. After injection, DCs migrate to draining lymph nodes and activate tumor-specific cytotoxic T-cells.

\section{GENE THERAPY}

Malignant pleural mesothelioma represents a good potential target disease for gene therapy. The disease is localized until late, is easily accessible, current therapies are inadequate and there is some evidence of immune responsiveness. Clinical trials of patients with MPM have established the safety of the intra-pleural delivery of replication-deficient adenoviral vectors expressing the suicide gene, herpes simplex thymidine kinase, followed by the administration of ganciclovir, an antiviral drug. Some evidence indicates that this approach induces an effective anti-tumor immune response (Sterman et al., 1998, 2005). Moreover, intra-pleural interferon- $\beta$ gene transfer with a replication-defective adenoviral vector may potentially be a useful approach for the generation of anti-tumor immune responses in MPM patients (Sterman et al., 2007). A significant obstacle to these approaches is the limited distribution of the non-replicative vectors within the tumor mass, even after direct intra-tumoral administration. Therefore, more efficient strategies for the virus to spread within tumors may be required to increase the clinical benefit. In a recent study, it was shown that intrathoracic administration of telomerase-specific oncolytic viruses induced significant anti-tumor effects against both pre-established and established pleural dissemination of human MPM (Watanabe et al., 2010). A phase I, dose-escalation study of telomerase-specific oncolytic adenovirus, OBP-301, is currently underway in the United States to assess the treatment feasibility and to characterize its pharmacokinetics in patients with advanced solid tumors. Phase II studies of telomerase-specific virotherapy in MPM patients are warranted. An phase I intra-pleural gene transfer study for pleural mesothelioma (IFN-alfa, SCH 721015, Ad.hIFN-a2b) is on-going (Anonymous, n.d.c). The effect of Ad. IFN is enhanced by combining with chemotherapy and phase I trials with this combination are in development.

\section{INVESTIGATIONAL SURGICAL APPROACHES}

In MPM, the role of surgery remains controversial and should be further explored. Although the multimodality treatment procedure seems feasible, overall treatment time is long and psychological distress is considerable. Subgroup analysis of a large Scandinavian phase II combination chemotherapy trial shows a median overall survival of 22 months in patients with good performance status, epithelioid subtype, stage I-II and aged 70 years or less, equivalent to survival in patients subjected to multimodality treatment (Hillerdal et al., 2008). These findings stress the importance of a large prospective multicentre, in which operable patients with early 
stage resectable MPM are randomly assigned to a surgical and a non-surgical management (Treasure et al., 2004). The feasibility of this approach has been explored in the UK MARS 1 trial, in which the randomization is between EPP followed by PORT and any palliative treatment, including pleurodesis, following an induction treatment with chemotherapy (Treasure et al., 2009). The results of the feasibility part of this trial have recently been released and show no difference in survival between both treatment arms (Treasure et al., 2010). A large retrospective uncontrolled series reports that $\mathrm{P} / \mathrm{D}$ might prolong survival as compared to EPP and that a less invasive procedure might hence be preferable in selected patients, provided it is standardized (Flores et al., 2008). In a systematic review of 1270 patients who had undergone lung-sparing surgery for mesothelioma (Teh et al., 2010), overall survival was comparable with the outcome reported in historical series including EPP. It is expected that a large European multicentre randomized trial will be conducted in the coming years, addressing the role of any tumor resection in MPM. Whether the latter will include EPP remains to be determined (Rusch, 2009).

\section{INVESTIGATIONAL RADIOTHERAPY APPROACHES}

As in NSCLC, the role of PORT in MPM is controversial and based on a single uncontrolled retrospective series. This additional value of PORT is being addressed in an on-going Swiss study, in which eligible patients are randomized after EPP between observation and hemi-thoracic PORT (Swiss Group for Clinical Cancer Research, 2009). Pleural IMRT allows administering a radical dose of radiotherapy to a MPM with intact lung (Rosenzweig et al., 2009). The role of IMRT with chemotherapy is presently being investigated in patients with irresectable disease (Anonymous, 2009k). Currently a study that looks at whether giving a short intense course of chest radiation just prior to surgery will sterilize these tumor cells and thus, avoid or reduce contamination of the areas outside the chest cavity is on-going. The investigators hypothesize that short neoadjuvant (pre-operative) hemi-thoracic IMRT, followed by immediate planned EPP ( \pm adjuvant chemotherapy) will reduce the risk of intra-operative seeding and reduce the incidence of distant metastatic disease (Anonymous, n.d. i).

Another trial explores the use of new radiation technology, tomotherapy, to treat mesothelioma more aggressively than has been possible before. Tomotherapy's ability to treat unusual shaped tumors, particularly when they are wrapped around sensitive normal tissues (the lung), enable higher doses of radiation to be used and this may improve its effectiveness (Anonymous, n.d. k).

An improved response has been seen in several studies where hyperthermia was added to radiotherapy. However, further investigation of this technique, which is not widely available, is required.

\section{ARRAY TECHNOLOGY IN MESOTHELIOMA}

With the advent of gene expression profiling frequent use of arrays has been carried out on MPM patient material, in attempts to identify profiles which may be predictive, prognostic or give information on treatment response (predictive of personalized therapy). Other groups have attempted to use gene expression microarrays to identify potential MPM biomarkers or important pathways which may be important for MPM pathogenesis. One of the problems identified with the use of array technology in MPM, has been the lack of concordance between the various predictive or prognostic studies (Gordon et al., 2003, 2005a; Pass et al., 2004; Glinsky et al., 2005; Lopez-Rios et al., 2006) Nevertheless, several of the genes identified in these predictive array studies have also shown up in other MPM array studies. Meta-analysis of the different mesothelioma studies may provide more robust prognostic genes which could be subsequently validated.

One emerging subset of genes which has been shown to be altered in mesothelioma concerns the insulin-like growth factor axis (Lee et al., 1993). With microarray analysis, several members of this axis have also been shown to be altered confirming the importance of this pathway in mesothelioma. Two commonly down-regulated genes from the IGF-axis in mesothelioma are IGFB-4 and IGFBP-5 (Kettunen et al., 2004), mainly overexpressed genes include IGFBP-2, IGFBP-3, IGFBP-7/MAC25, and an exon specific isoform of IGF-I (IGF-I, exon 1A; Hoang et al., 2004; Mohr et al., 2004; Gordon et al., 2005b; Anonymous, n.d. g) be noted that IGFBP-3 is another gene whose overexpression has also been linked to poor outcome tumors (Gordon et al., 2005b) indicating that a comprehensive analysis of the IGFBP family may have clinical value in MPM. A Phase II Study of IMC-A12, an antibody that is designed to block the effects of a protein called Type I Insulin-Like Growth Factor (IGF-1R), in patients with mesothelioma who have been previously treated with chemotherapy is on-going (Anonymous, n.d. g).

\section{CONCLUSION}

The last decade has seen some important changes in the management of mesothelioma. We now have active first-line chemotherapy available, which will not only moderately increase survival but will also help in relieving symptoms. But most of patients will have relapse after first-line chemotherapy and their survival is poor. The molecular biologic research should focus on mesothelioma-specific pathways and biomarkers; this is the only way to move forward and to explore novel, more active therapeutic options and better treatments for this disease. A small proportion of patients might benefit from more aggressive (surgical) interventions with radical or even curative intent. It is our duty as physicians to inform our patients about all treatment options available but also to protect them from potential harmful or useless therapies. As with any rare disease, referral of the patients with MPM to a center with extensive experience and expertise with this disease is recommended to enhance the probability of accruing these patients into clinical trials.

Recent progress has reshaped the clinical landscape in the treatment of MPM. We have now more effective chemotherapy and from current evidence, it is clear that histone deacetylase inhibitors represent a potentially new treatment modality in MPM. Among current investigational drugs, mesothelin targeted therapies, dendritic cell based immunotherapy, and gene therapy hold promise and should be further explored. Despite these, actual treatment is still amenable to improvement. Several factors have hampered the development of more effective regimens for mesothelioma. MPM is uncommon, is heterogeneous, staging is unreliable, response assessment is difficult and most drugs do not work. For the staging, the International Mesothelioma Interest Group are actually collaborating with the IASLC to include MPM in its proposals for the eighth edition of 
TNM classification. The ability to measure reproducibly tumor response to treatment is vital in the development of new drugs and therapeutic combinations, particularly for the conducting of phase II studies. Conventional response criteria have always been difficult to apply to malignant mesothelioma due to its unique pattern of growth. Because the selection of measurement sites in mesothelioma is difficult, RECIST criteria could be applied differently by different investigators and that's why the Modified RECIST criteria have been developed. Based on the complex growth pattern of MPM, response evaluation in this cancer entity is still challenging. Results on value of fluoro-2-deoxy-D-glucose and positron emission tomography imaging [SUV mean, tumor lesion glycolysis (TLG), and tumor volume (PETvol)] in response assessment in MPM are promising.

Where do we go from here with the systemic therapy for MPM? We need better drugs, probably by more accurate preclinical investigation and we have to use better the drugs we have: in maintenance therapy, in special populations, in multimodality setting. More selectivity regarding the "promising" drug we choose to move from the bench to the clinic and fewer "me too" trials are warranted. Better designed trials that are adequately powered, multicentre, preferable with randomized phase II design to balance for heterogeneity, with appropriate endpoints (PFS, OS, QoL) and with correlative studies built in, are mandatory. Methods to assay individual tumor characteristics are warranted in order to avoid toxicity in patients who may not respond to treatment and losing precious time in a disease associated with a short survival. Drug resistance profiles have been reported to various malignant diseases including NSCLC, SCLC, breast, ovarian, colon, esophageal, and carcinoid tumors. Recently the feasibility of performing off-site in vitro drug resistance assays on resected mesothelioma specimens is reported.

\section{REFERENCES}

Ahamed, A., Stevens, C. W., Smyth, W. R., Vaporciyan, A. A., Komaki, R., Kelly, J. F., Liao, Z., Starkschall, G., and Forster, K. M. (2003). Intensity-modulated radiation therapy: a novel approach to the management of malignant pleural mesothelioma. Int. J. Radiat. Oncol. Biol. Phys. 355, 768-775.

Allen, A. L., Czerminska, M., Janne, P. A., Sugarbaker, D. J., Bueno, R., Harris, J. R., Court, L., and Baldini, E. H. (2006). Fatal pneumonitis associated with intensity-modulated radiation therapy for mesothelioma. Int. J. Radiat. Oncol. Biol. Phys. 65, 640-645.

Anonymous. (n.d. a). Dasatinib in Resectable Malignant Pleural Mesothelioma, NCT00652574. Available at: http://www.clinicaltrials.gov [accessed January 03, 2011].

Anonymous. (n.d. b). Dasatinib in Treating Patients With Previously Treated Malignant Mesothelioma, NCT00509041. Available at: http:// www.clinicaltrials.gov [accessed January 03, 2011].

Anonymous. (n.d. c). Intrapleural Gene Transfer for Pleural Mesothelioma
(IFN-alpha), NCT01212367. Available at: http://www.clinicaltrials.gov [accessed January 2011].

Anonymous. (n.d. d). Pemetrexed Disodium and Cisplatin With or Without Cediranib Maleate in Treating Patients with Malignant Pleural Mesothelioma NCT01064648. Available at: http://www.clinicaltrials. gov [accessed January 03, 2011].

Anonymous. (n.d. e). Phase I/II Study of a Triplet Combination of CBP501, Pemetrexed and Cisplatin in Patients With Advanced Solid Tumors and in Chemotherapy-naïve Patients With Malignant Pleural Mesothelioma. NCT00700336. Available at: http:// www.clinicaltrials.gov [accessed January 03, 2011].

Anonymous. (n.d. f). Phase II Study Of ET-743 In Patients With Unresectable Malignant Pleural Mesothelioma. NCT00027508. Available at: http:// www.clinicaltrials.gov [accessed January 03, 2011].

Anonymous. (n.d. g). Phase II Study of IMC-A12 in Patients With Mesothelioma Who Have Been Previously Treated With Chemotherapy,

For clinical implementation, a chemo resistance test applicable to pemetrexed should be useful. The effectiveness of assay-directed therapy is promising and need to be addressed in prospective trials.

Multiple biologicals have been studied or are still under investigation, however a lot of them seems to fail. It is of great importance that the molecular biologic research should focus more on mesothelioma-specific pathways and biomarkers, instead of copying mechanisms and treatments that were successful in other tumor types. Looking at the list of new VEGFR-inhibitors being tested in MPM, one can question if it is a wise use of the limited patient resources to perform so many "me too" trials in this uncommon disease? One can question whether trials with so-called targeted agents in an unselected population of mesothelioma patients are appropriate.

With the use of array technology there will be certainly an implicit gain in the identification of new potential prognostic or biomarkers or important pathways in the MPM pathogenesis, which can individually be worked up for independent validation. The concern for many researchers is the lack of concordance between studies. Nevertheless, an potential successful approach may be to collate all the available data to a database to identify networks of MPM pathways which might allow for the identification of novel therapeutic approaches for the treatment of MPM. Research funders and the research community should consider the need for enhanced coordination and collaboration. The currently paucity of treatment options with good clinical outcome for MPM means also that significant research remains to discover biomarkers for the early detection of MPM. Suggestions to develop a central mesothelioma virtual tissue bank may also contribute to the ultimate goal to identify druggable targets and to develop personalized treatment for the MPM patients.

NCT01160458. Available at: http:// www.clinicaltrials.gov [accessed January 03, 2011].

Anonymous. (n.d. h). Randomized Study of Adjuvant WT-1 Analog Peptide Vaccine in Patients With Malignant Pleural Mesothelioma (MPM) After Completion of Combined Modality Therapy, NCT01265433, accessed January 03, 2011 http://www.clinicaltrials.gov

Anonymous. (n.d. i). Short Neoadjuvant Hemithoracic IMRT for MPM, NCT00797719. Available at: http:// www.clinicaltrials.gov/ct2/show/ [accessed January 03, 2011].

Anonymous. (n.d. j). Study of Safety and Tolerability of Intravenous CRS-207 in Adults With Selected Advanced Solid Tumors Who Have Failed or Who Are Not Candidates for StandardTreatment, NCT00585845. Available at: http:// www.clinicaltrials.gov [accessed January 03, 2011].

Anonymous. (n.d. k). Tomotherapy Treatment for Mesothelioma, NCT00469196. Available at: http:// www.clinicaltrials.gov/ct2/show/ [accessed January 03, 2011].
Anonymous. (2009a). A phase II Study of the Association of Glivec ${ }^{\circledR}$ Plus Gemzar ${ }^{\circledR}$ in Patients with Unresectable, Refractory, Malignant Mesothelioma NCT00551252. Available at: http:// www.clinicaltrials.gov [accessed January 03, 2011].

Anonymous. (2009b). A Study of Cetuximab Combined With Cisplatin or Carboplatin/Pemetrexed As First Line Treatment in Patients with Malignant Pleural Mesothelioma, Mesomab Nct00996567. Available at: http://www.clinicaltrials.gov [accessed January 03, 2011].

Anonymous. (2009c). A Study to Find the Best Dose of SU011248 When Given with Pemetrexed, Pemetrexed and Cisplatin or Pemetrexed and Carboplatin in Patients with Advanced Solid Tumours NCT00528619. Available at: http://www.clinicaltrials.gov [accessed January 03, 2011].

Anonymous. (2009d). A Study of MORAb009 in Subjects with Pancreatic Cancer, Mesothelioma or Certain Types of Ovarian or Lung Cancer NCT00325494. Available at: http://www.clinicaltrials. gov [accessed January 03, 2011]. 
Anonymous. (2009e). Bevacizumab (Avastin) and Erlotinib (Tarceva) in Previously Treated Mesothelioma NCT00137826. Available at: http:// www.clinicaltrials.gov [accessed January 03, 2011].

Anonymous. (2009f). Bortezomib and Cisplatin as First-Line Therapy in Treating Patients with Malignant Mesothelima NCT00458913. Available at: http://www.clinicaltrials.gov [accessed January 03, 2011].

Anonymous. (2009g). Bortezomib in Treating Patients with Malignant Pleural Mesothelioma NCT00325494. Available at: http://www.clinicaltrials. gov [accessed January 03, 2011].

Anonymous. (2009h). Cisplatin, Pemetrexed and Imatinib Mesylate in Malignant Mesothelioma NCT00402766. Available at: http:// www.clinicaltrials.gov [accessed January 03, 2011].

Anonymous. (2009i). PXD101 as SecondLine Therapy in Treating Patients with Malignant Mesothelioma of the Chest that Cannot be Removed by Surgery NCT00365053. Available at: http:// www.clinicaltrials.gov [accessed January 03, 2011].

Anonymous.(2009j). Sorafenib in Treating Patients with Malignant Mesothelioma NCT00107432. Available at: http:// www.clinicaltrials.gov [accessed January 03, 2011].

Anonymous. (2009k). Study Using Chemotherapy Followed By Intensity Modulated Radiation Therapy To The Pleura In Patients With Locally Advanced But Unresectable Malignant pleural Mesothelioma NCT00715611. Available at: http://www.clinicaltrials. gov/ct2/show/ [accessed on November 3, 2009].

Anonymous. (20091). Suberoylanilide Hydroxamic Acid Vorinostat, MK0683 Versus Placebo in Advanced Malignant Pleural Mesothelioma NCT00128102. Available at: http://www.clinicaltrials. gov [accessed January 03, 2011].

Anonymous. (2009m). Sunitinib in Treating Patients with Advanced Malignant Pleural Mesothelioma NCT00392444. Available at: http:// www.clinicaltrials.gov [accessed January 03, 2011].

Anonymous. (2010). Monoclonal Antibody (GC1008) in Relapsed Malignant Pleural Mesothelioma 12293. Available at: http://www.clinicaltrials.gov [accessed January 03, 2011].

Baas, P., Boogerd, W., Dalesio, O., Haringhuizen, A., Custers, F., and van Zandwijk, N. (2005). Thalidomide in patients with malignant pleural mesotheliom. Lung Cancer 48, 291-296.

Baas, P, Buikhuisen, W, Dalesio, O, Vincent, A., Pavlakis, N., Van Klaveren, R.,
Schramel, F., Custers, F., Schouwink, H., Burgers, S. A., Netherlands Cancer Institute, Amsterdam, Netherlands, The Netherlands Cancer Institute - Antoni van Leeuwenhoek hospital, Amsterdam, Netherlands, Royal North Shore Hospital, Sydney University, Sydney, Australia, Erasmus University Medical Center, Rotterdam, Netherlands; St Antonius Hospital, Nieuwegein, Netherlands; Atrium Hospital, Heerlen, Netherlands, Medisch Spectrum Twente, Enschede, Netherlands, and The Netherlands Cancer Institute, Amsterdam, Netherlands. (2011). A multicenter, randomized phase III maintenance study of thalidomide (arm A) versus observation (arm B) in patients with malignant pleural mesothelioma (MPM) after induction chemotherapy. J. Clin. Oncol. 29(Suppl.). [abstract 7006]

Baldini, E. H., Recht, A., Strauss, G. M., DeCamp MM, J. r., Swanson, S. J., Liptay, M. J., Mentzer, S. J., and Sugarbaker, D. J. (1997). Patterns of failure after trimodality therapy for malignant pleural mesothelioma. Ann. Thorac. Surg. 63, 334-338.

Banchereau, J., and Palucka, A. K. (2005). Dendritic cells as therapeutic vaccines against cancer. Nat. Rev. Immunol. 5, 296-306.

Berghmans, T., Lafitte, J.-J., Mascaux, C., Meert,A.-P., Paesmans, M., and Sculier, J.-P. (2003). Activity of chemotherapy and immunotherapy on malignant mesothelioma: a systematic review of the literature with meta-analysis. Lung Cancer 41, 245-256.

Bertino, P., Porta, C., Barbone, D., Germano, S., Busacca, S., Pinato, S., Tassi, G., Favoni, R., Gaudino, G., and Mutti, L. (2007). Preliminary data suggestive of a novel translational approach to mesothelioma treatment: imatinib mesylate with gemcitabine or pemetrexed. Thorax 62, 690-695.

Branchaud, R. M., MacDonald, J. L., and Kane, A. B. (1989). Induction of angiogenesis by intraperitoneal injection of asbestos fibers. FASEB J. 3, 1747-1752.

Brockstedt, G., Giedlin, M. A., Leong, M. L., Bahjat, K. S., Gao, Y., Luckett, W., Liu, W., Cook, D. N., Portnoy, D. A., and Dubensky, T. W. Jr. (2004). Listeria-based cancer vaccines that segregate immunogenicity from toxicity. Proc. Natl. Acad. Sci. U.S.A. 101, 13832-13837.

Ceresoli, G., Castagneto, B., Zucali, P. A., Favaretto, A., Mencoboni, M., Grossi, F., Cortinovis, D., Del Conte, G., Ceribelli, A., Bearz, A., Salamina, S., De Vincenzo, F., Cappuzzo, F., Marangolo, M., Torri, V., and Santoro, A. (2008).
Pemetrexed plus carboplatin in elderly patients with malignant pleural mesothelioma: combined analysis of two phase II trials. Br. J. Cancer 99, 51-56.

Chang, K., Pai, L. H., Pass, H., Pogrebniak, H. W., Tsao, M. S., Pastan, I., and Willingham, M. C. (1992). Monoclonal antibody K1 reacts with epithelial mesothelioma but not lung adenocarcinoma. Am. J. Surg. Pathol. 16, 259-268.

Chapman, E., Berenstein, G., García Diéguez, M., and Ortiz, Z. (2006). Radiotherapy for malignant pleural mesothelioma. Cochrane Database Syst. Rev. 3:CD003880.

Chowdhury, S., and Pastan, I. (1999). Improving antibody affinity by mimicking somatic hypermutation in vitro. Nat. Biotechnol. 17, 568-572.

Chowdhury, S, Viner, J. L., Beers, R., and Pastan, I. (1998). Isolation of a highaffinity stable single-chain Fv specific for mesothelin from DNA-immunized mice by phage display and construction of a recombinant immunotoxin with anti-tumor activity. Proc. Natl. Acad. Sci. U. S. A 25, 669-674.

Cortese, J. F., Gowda, A. L., Wali, A., Eliason, J. F., Pass, H. I., and Everson, R. B. (2006). Common EGFR mutations conferring sensitivity to gefitinib in lung adenocarcinoma are not prevalent in human malignant mesothelioma. Int. J. Cancer 118, 521-522.

Cranmer, L. D., Trevor, K. T., and Hersh, E. M. (2004). Clinical applications of dendritic cell vaccination in the treatment of cancer. Cancer Immunol. Immunother. 53, 275-306

Dazzi, H., Hasleton, P. S., Thatcher, N. Wilkes, S., Swindell, R., and Chatterjee, A. K. (1990). Malignant pleural mesothelioma and epidermal growth factor receptor, relationship of EGF-R with histology and survival using fixed paraffin embedded tissue and the F4, monoclonal antibody. Br. J. Cancer 61, 924-926.

De Perrot, M., Feld, R., Cho, B. C., Bezjak, A., Anraku, M., Burkes, R., Roberts, H., Tsao, M. S., Leighl, N., Keshavjee, S., and Johnston, M. R. (2009). Trimodality therapy with induction chemotherapy followed by extrapleural pneumonectomy and adjuvant high-dose hemithoracic radiation for malignant pleural mesothelioma. J. Clin. Oncol. 27, 1413-1418.

Deroanne, C. F., Bonjean, K., Servotte, S., Devy, L., Colige, A., Clausse, N., Blacher, S., Verdin, E., Foidart, J. M., Nusgens, B. V., and Castronovo, V. (2002). Histone deacetylases inhibitors as anti-angiogenic agents altering vascular endothelial growth factor signalling. Oncogene 21, 427-436.
Edwards, J. G., Cox, G., Andi, A., Jones, J. L., Walker, R. A., Waller, D. A., and O’Byrne, K. J. (2001). Angiogenesis is an independent prognostic factor in malignant mesothelioma.Br. J. Cancer 85, 863-868.

Ellis, P., Davies, A., Evans, K., Haynes, A. E., Lloyd, N. S., and Lung Cancer Disease Site Group of Cancer Care Ontario's Program in Evidence-based Care. (2006). The use of chemotherapy in patients with advanced malignant pleural mesothelioma: a systematic review and practice guideline. $J$. Thorac. Oncol. 1, 591-601.

Fennell, D. A., Chacko, A., and Mutti, L. (2008). BCL-2 family regulation by the 20 S proteasome inhibitor bortezomib. Oncogene 27, 1189-1197.

Fennell, D. A., Steele, J. P., Shamash, J., Evans, M. T., Wells, P., Sheaff, M. T., Rudd, R. M., and Stebbing, J. (2007). Efficacy and safety of first- or second-line irinotecan, cisplatin, and mitomycin in mesothelioma. Cancer 109, 93-99.

Flores, R. M., Krug, L. M., Rosenzweig, K. E., Venkatraman, E., Vincent, A., Heelan, R., Akhurst, T., and Rusch, V. W. (2006). Induction chemotherapy, extrapleural pneumonectomy, and postoperative high-dose radiotherapy for locally advanced malignant pleural mesothelioma: a phase II trial. J. Thorac. Oncol. 1, 289-295.

Flores, R. M., Pass, H. I., Seshan, V. E., Dycoco, J., Zakowski, M., Carbone, M., Bains, M. S., and Rusch, V. W. (2008). Extrapleural pneumonectomy (EPP) versus pleurectomy/ decortication (P/D) in the surgical management of malignant pleural mesothelioma (MPM): results in 663 patients. J. Thorac. Cardiovasc. Surg. $135,620-626$

Garland, L. L., Rankin, C., Gandara, D. R., Rivkin, S. E., Scott, K. M., Nagle, R. B., Klein-Szanto, A. J., Testa, J. R., Altomare, D. A., and Borden, E. C. (2007). Phase II study of erlotinib in patients with malignant pleural mesothelioma: a Southwest Oncology Group Study. J. Clin. Oncol. 25, 2406-2413.

Giaccone, G., O’Brien, M. E., Byrne, M. J., Bard, M., Kaukel, E., and Smit, B. (2002a). Phase II trial of ZD0473 as second-line therapy in mesothelioma. Eur. J. Cancer 38(Suppl. 8), S19-S24.

Giaccone, G., O’Brien, M., Byrne, M., Barde, M., Kaukelf, E., and Smit, B. (2002b). Current phase II data for ZD0473 in patients with mesothelioma who had relapsed following one prior chemotherapy regimen. Eur. J. Cancer 38(Suppl. 8), S19-S24.

Giedlin, M. A., Bahjat, K. S., Prell, R. A., et al. (2007). "Activation and 
expansion of hepatic NK cells promotes innate antitumor immunity and long-lived CD8+ $\mathrm{T}$ cell memory following treatment with attenuated Listeria monocytogenes," in $A A C R$ Proceedings [Abstract\#1877, April 14]

Gish, R. G., Porta, C., Lazar, L., Ruff, P., Feld, R., Croitoru, A., Feun, L., Jeziorski, K., Leighton, J., Gallo, J., and Kennealey, G. T. (2007). Phase III randomized controlled trial comparing the survival of patients with unresectable hepatocellular carcinoma treated with nolatrexed or doxorubicin. J. Clin. Oncol. 25, 3069-3075.

Glinsky, G.V., Berezovska, O., and Glinskii, A. B. (2005). Microarray analysis identifies a death-from-cancer signature predicting therapy failure in patients with multiple types of cancer. J. Clin. Invest. 115, 1503-1521.

Gordon, G. J., Jensen, R. V., Hsiao, L. L., Gullans, S. R., Blumenstock, J. E., Richards, W. G., Jaklitsch, M. T., Sugarbaker, D. J., and Bueno, R. (2003). Using gene expression ratios to predict outcome among patients with mesothelioma. J. Natl. Cancer Inst. 95, 598-605.

Gordon, G. J., Mani, M., Maulik, G., Mukhopadhyay, L., Yeap, B. Y., Kindler, H. L., Salgia, R., Sugarbaker, D. J., and Bueno, R.(2007). Preclinical studies of the proteasome inhibitor bortezomib in malignant pleural mesothelioma. Cancer Chemother. Pharmacol. 10,1007.

Gordon, G. J., Rockwell, G. N., Godfrey, P. A., Jensen, R. V., Glickman, J. N., Yeap, B. Y., Richards, W. G., Sugarbaker, D. J., and Bueno, R. (2005a). Validation of genomics-based prognostic tests in malignant pleural mesothelioma. Clin. Cancer Res. 11, 4406-4414.

Gordon, G. J., Rockwell, G. N., Jensen, R. V., Rheinwald, J. G., Glickman, J. N., Aronson, J. P., Pottorf, B. J., Nitz, M. D., Richards, W. G., Sugarbaker, D. J., and Bueno, R. (2005b). Identification of novel candidate oncogenes and tumor suppressors in malignant pleural mesothelioma using largescale transcriptional profiling. Am. J. Pathol. 166, 1827-1840.

Govindan, R., Kratzke, R. A., Herndon, J. E. II, Niehans, G. A., Vollmer, R., Watson, D., Green, M. R., Kindler, H. L., and Cancer and Leukemia Group B (CALGB 30101). (2005). Gefitinib in patients with malignant mesothelioma: a phase II study by the Cancer and Leukemia Group B. Clin. Cancer Res. 11, 2300-2304.

Halstead, J. C., Lim, E., Venkateswaran, R. M., Charman, S. C., Goddard, M., and Ritchie, A. J. (2005). Improved survival with VATS pleurectomy-decortication in advanced malignant mesothelioma. Eur. J. Surg. Oncol. 31, 314-320.
Harvey, V. J., Slevin, M. L., Ponder, B. A., Blackshaw, A. J., and Wrigley, P. F. (1984). Chemotherapy of diffuse malignant mesothelioma, phase II trials of single-agent 5 -fluorouracil and adriamycin. Cancer 54, 961-964.

Hassan, R., Bullock, S., Premkumar, A., Kreitman, R. J., Kindler, H., Willingham, M. C., and Pastan, I. (2007). Phase I study of SS1P, a recombinant anti-mesothelin immunotoxin given as a bolus IV infusion to patients with mesotheline expressing mesothelioma, ovarian and pancreatic cancers. Clin. Cancer Res. 13, 5144-5149.

Hegmans, J. P., Hemmes, A., Aerts, J. G., Hoogsteden, H. C., and Lambrecht, B. N. (2005). Immunotherapy of murine malignant mesothelioma using tumour lysate-pulsed dendritic cells. Am. J. Respir. Crit. Care Med. 171, 1168-1177.

Hegmans, J. P., Hemmes, A., Hammad, H., Boon, L., Hoogsteden, H. C., and Lambrecht, B. N. (2006). Mesothelioma environment comprises cytokines and T-regulatory cells that suppress immune responses. Eur. Respir. J. 27, 1086-1095.

Hillerdal, G., Sorensen, J. B., Sundström, S., Riska, H., Vikström, A., and Hjerpe, A. (2008). Treatment of malignant pleural mesothelioma with carboplatin, liposomized doxorubicin, and gemcitabine: a phase II study. J. Thorac. Oncol. 3, 1325-1331.

Ho, M., Hassan, R., Zhang, J., Wang, Q. C., Onda, M., Bera, T., and Pastan, I. (2005). Humoral immune response to mesothelin in mesothelioma and ovarian cancer patients. Clin. Cancer Res. 11, 3814-3820.

Hoang, C. D., D’Cunha, J., Kratzke, M. G., Casmey, C. E., Frizelle, S. P., Maddaus, M. A., and Kratzke, R. A. (2004). Gene expression profiling identifies matriptase overexpression in malignant mesothelioma. Chest 125, 1843-1852.

Hughes, A. N., Rafi, I., Griffin, M. J., Calvert, A. H., Newell, D. R., Calvete, J. A., Johnston, A., Clendeninn, N., and Boddy, A. V. (1999). Phase I studies with the nonclassical antifolate nolatrexed dihydrochloride (AG337, THYMITAQ) administered orally for 5 days. Clin. Cancer Res. 5, 111-118.

Jaffee, E.M., Hruban, R.H., Biedrzycki, B., Laheru, D., Schepers, K., Sauter, P. R., Goemann, M., Coleman, J., Grochow, L., Donehower, R. C., Lillemoe, K. D., O'Reilly, S., Abrams, R. A., Pardoll, D. M., Cameron, J. L., and Yeo, C. J. (2001). Novel allogeneic granulocyte-macrophage colony-stimulating factor-secreting tumor vaccine for pancreatic cancer: a phase I trial of safety and immune activation. J. Clin. Oncol. 19, 145-156.
Jahan, T. M., Gu, L., Wang, X., Kratzke, R. A., Dudek, A. Z., Green, M. R., Vokes, E. E., and Kindler, H. L. (2006) Vatalanib (V) for patients with previously untreated advanced malignant mesothelioma (MM): a phase II study by the Cancer and Leukemia Group B (CALGB 30107).J. Clin. Oncol. (Suppl. 18), 24 [abstract no. 7081].

Janne, P., Wang, X., Krug, L., Hodgson, L. Vokes, E. E., and Kindler, H. L. (2007). Sorafenib in malignant mesothelioma (MM): a phase II trial of the Cancer and Leukemia Group B (CALGB 30307). J. Clin. Oncol. 25 [abstract no. 7707].

Jassem, J., Ramlau, R., Santoro, A., Schuette, W., Chemaissani, A., Hong, S., Blatter, J., Adachi, S., Hanauske, A., and Manegold, C. (2008). Phase III trial of pemetrexed plus best supportive care compared with best supportive care in previously treated patients with advanced malignant pleural mesothelioma. J. Clin. Oncol. 26, 1698-1704.

Jotte, R., Conkling, P., Reynolds, C., Galsky, M. D., Klein, L., Fitzgibbons, J. F., McNally, R., Renschler, M. F., and Oliver,J.W. (2010). Randomized phase II trial of single-agent amrubicin or topotecan as second-line treatment in patients with small-cell lung cancer sensitive to first-line platinum-based chemotherapy.J. Clin. Oncol. 6. [Epub ahead of print].

Karrison, T., Kindler, H., Gandara, D., Lu, C., Guterz, T. L., Nichols, K., Chen, H., Stadler, W.M., and Vokes, E. E. (2007). Final analysis of a multi-centre, double-lind, placebo-controlled, randomised phase II trial of gemcitabine/ cisplatin (GC) plus bevacizumab (B) or placebo $(\mathrm{P})$ in patients (pts) with malignant mesothelioma (MM). J. Clin. Oncol. 25. [abstract no. 7526].

Kelland, L. (2007). The resurgence of platinum-based cancer chemotherapy. Nat. Rev. Cancer 7, 573-584.

Kettunen, E., Vivo, C., Gattacceca, F., Knuutila, S., Jaurand, M. C. (2004). Gene expression profiles in human mesothelioma cell lines in response to interferon-gamma treatment. Cancer Genet. Cytogenet. 152, 42-51.

Kindler, H. L., Burris, H. A. III, Sandler, A. B., and Oliff, I. A. (2009). A phase II multicenter study of L-alanosine, a potent inhibitor of adenine biosynthesis, in patients with MTAP-deficient cancer. Invest. New Drugs 27, 75-81.

Klabatsa, A., Sheaff, M. T., Steele, J. P., Evans, M. T., Rudd, R. M., and Fennell, D. A. (2006). Expression and prognostic significance of hypoxia-inducible factor lalpha (HIF-1alpha) in malignant pleural mesothelioma (MPM). Lung Cancer 51, 53-59.
Krug, L. M., Curley, T., Schwartz, L., Richardson, S., Marks, P., Chiao, J., and Kelly, W. K. (2006). Potential role of histone deacetylase inhibitors in mesothelioma: clinical experience with suberoylanilide hydroxamic acid. Clin. Lung Cancer 7, 257-261.

Krug, L. M., Heelan, R. T., Kris, M. G., Venkatraman, E., and Sirotnak, F. M. (2007). Phase II trial of pralatrexate (10-propargyl-10-deazaaminopterin, PDX) in patients with unresectable malignant pleural mesothelioma. J. Thorac. Oncol. 2, 317-320.

Krug, L. M., Pass, H. I., Rusch, V. W., Kindler, H. L., Sugarbaker, D. J., Rosenzweig, K. E., Flores, R., Friedberg, J. S., Pisters, K., Monberg, M., Obasaju, C. K., and Vogelzang, N. J. (2009). Multicentre phase II trial of neoadjuvant pemetrexed plus cisplatin followed by extrapleural pneumonectomy and radiation for malignant pleural mesothelioma. J. Clin. Oncol. 27, 3007-3013.

Kumar-Singh, S., Weyler, J., Martin, M. J., Vermeulen, P. B., and Van Marck, E. (1999). Angiogenic cytokines in mesothelioma: a study of VEGF, FGF-1 and -2 , and TGF beta expression. J. Pathol. $189,72-78$.

Lee, T. C., Zhang, Y., Aston, C., Hintz, R., Jagirdar, J., Perle, M. A., Burt, M., and Rom, W. N. (1993). Normal human mesothelial cells and mesothelioma cell lines express insulin-like growth factor I and associated molecules. Cancer Res. 53, 2858-2864.

Lopez-Rios, F., Chuai, S., Flores, R., Shimizu, S., Ohno, T., Wakahara, K., Illei, P. B., Hussain, S., Krug, L., Zakowski, M. F., Rusch, V., Olshen, A. B., and Ladanyi, M. (2006). Global gene expression profiling of pleural mesotheliomas: overexpression of aurora kinases and P16/CDKN2A deletion as prognostic factors and critical evaluation of microarraybased prognostic prediction. Cancer Res. 66, 2970-2979.

Maasilta, P. (1991). Deterioration in lung function following hemithorax irradiation for pleural mesothelioma. Int. J. Radiat. Oncol. Biol. Phys. 20, 433-438.

Marks, P. A., Richon, V. M., Breslow, R., and Rifkind, R. A. (2001). Histone deacetylase inhibitors as new cancer drugs. Curr. Opin. Oncol. 13, 477-483.

Martin-Ucar, A. E., Edwards, J. G., Rengajaran, A., Muller, S., and Waller, D. A. (2001). Palliative surgical debulking in malignant mesothelioma. Predictors of survival and symptom control. Eur. J. Cardiothorac. Surg. 20, 1117-1121.

Mathy, A., Baas, P., Dalesio, O., and van Zandwijk, N. (2005). Limited efficacy of imatinib mesylate in malignant 
mesothelioma: a phase II trial. Lung Cancer 50, 83-86.

May, R. J., Dao, C., Pinilla-Ibarz, J., Korontsvit, T., Zakhaleva, V., Zhang, R. H., Maslak, P., and Scheinberg, D. A. (2007). Peptide epitopes from the Wilms' tumour 1 oncoprotein stimulate CD4+ and CD8+ T-cells that recognize and kill human malignant mesothelioma tumour cells. Clin. Cancer Res. 13, 4547-4555.

Millward, W., Parnis, F., Byrne, M., Powell, A., Dunleavey, R., Lynch, K., and Boyer, M. J. (2003). Phase II trial of imatinib mesylate in patients with advanced pleural mesothelioma. Proc. Am. Soc. Clin. Oncol. 22. [abstract no. 912].

Mohr, S., Bottin, M. C., Lannes, B., Neuville, A., Bellocq, J.P., Keith, G., and Rihn, B. H. (2004). Microdissection, mRNA amplification and microarray: a study of pleural mesothelial and malignant mesothelioma cells. Biochimie 86, 13-19.

Muirhead, R., and O'Rourke, N. (2007). Drain site radiotherapy in malignant pleural mesothelioma: a wasted resource. Eur. Res. J. 30, 1021.

Nakas, A., Martin-Ucar, A. E., Edwards, J. G., and Waller, D.A. (2008). The role of video assisted thoracoscopic pleurectomy/decortication in the therapeutic management of malignant pleural mesothelioma. Eur. J. Cardiothorac. Surg. 33, 83-88.

Nowak, A. K., Millward, M. J., Francis, R., van der Schaaf, A., Musk, A. W., and Byrne, M. J. (2008). Phase II study of sunitinib as second-line therapy in malignant pleural mesothelioma (MPM). J. Clin. Oncol. 26(Suppl.), 439s. [abstract 8063].

Ohta, Y., Shridhar, V., Bright, R. K., Kalemkerian, G. P., Du, W., Carbone, M., Watanabe, Y., and Pass, H. I. (1999). VEGF and VEGF type C play an important role in angiogenesis and lymphangiogenesis in human malignant mesothelioma tumours. $\mathrm{Br}$. J. Cancer 1, 54-61.

Opitz, I., Kestenholz, P., Lardinois, D., Müller, M., Rousson, V., Schneiter, D., Stahel, R., and Weder, W. (2006). Incidence and management of complications after neoadjuvant chemotherapy followed by extrapleural pneumonectomy for malignant pleural mesothelioma. Eur. J. Cardiothorac. Surg. 29, 579-584.

Ordanez, N. G. (2007). What are the current best immunohistochemical markers for the diagnosis of epithelioid mesothelioma: a review and update. Hum. Pathol. 38, 1-6.

Ordonez,N.G. (2003). Value of mesothelin immunostaining in the diagnosis of mesothelioma, Mod. Pathol. 16, 192-197.
Pass, H. I., Liu, Z., Wali, A., Bueno, R., Land, S., Lott, D., Siddiq, F., Lonardo, F., Carbone, M., and Draghici, S. (2004). Gene expression profiles predict survival and progression of pleural mesothelioma. Clin. Cancer Res. 10, 849-859.

Pavlakis, N., Abraham, R., and Harvie, R. (2003). Thalidomide alone or in combination with cisplatin/gemcitabine in malignant pleural mesothelioma: interim results from two parallel non randomised phase II studies. Lung Cancer 41(Suppl. 2), S11. [abstract].

Porta, C., Mutti, L., and Tassi, G. (2007). Negative results of an Italian group for mesothelioma (G.I.Me.) pilot study of single-agent imatinib mesylate in malignant pleural mesothelioma. Cancer Chemother. Pharmacol. 59, 149-150.

Porta, C., Zimatore, M., Bonomi, L., Imarisio, I., Paglino, C., SartoreBianchi, A., and Mutti, L. (2005). Raltitrexed-oxaliplatin combination chemotherapy is inactive as secondline treatment for malignant pleural mesothelioma patients. Lung Cancer 48, 429-434.

Raymond, E., Alexandre, J., Faivre, S., Vera, K., Materman, E., Boni, J., Leister, C., Korth-Bradley, J., Hanauske, A., and Armand, J. P. (2004). Safety and pharmacokinetics of escalated doses of weekly intravenous infusion of CCI-779, a novel mTOR inhibitor, in patients with cancer.J. Clin. Oncol. 22, 2336-2347.

Rice, D. C., Stevens, C. W., Correa, A. M., Vaporciyan, A. A., Tsao, A., Forster, K. M., Walsh, G. L., Swisher, S. G., Hofstetter, W. L., Mehran, R. J., Roth, J. A., Liao, Z., and Smythe, W. R. (2007). Outcomes after extrapleural pneumonectomy and intensity-modulated radiation therapy for malignant pleural mesothelioma. Ann. Thorac. Surg. 84, 1685-1692.

Richly, H., Henning, B. F., Kupsch, P., Passarge, K., Grubert, M., Hilger, R. A., Christensen, O., Brendel, E., Schwartz, B., Ludwig, M., Flashar, C., Voigtmann, R., Scheulen, M. E., Seeber, S., and Strumberg, D. (2006). Results of a Phase I trial of sorafenib (BAY 43-9006) in combination with doxorubicin in patients with refractory solid tumours. Ann. Oncol. 17, 866-873.

Righi, L., Papotti, M. G., Ceppi, P., Billè, A., Bacillo, E., Molinaro, L., Ruffini, E., Scagliotti, G. V., and Selvaggi, G. (2010). Thymidylate synthase but not excision repair cross-complementation group 1 tumor expression predicts outcome in patients with malignant pleural mesothelioma treated with pemetrexed-based chemotherapy. J. Clin. Oncol. 28, 1534-1539.

Rosenzweig, K., Krug, L., Laser, B., Yorke, E., Flores, R., Brown, A., and Rusch, V. W. (2009). Feasibility of pleural intensity-modulated radiation therapy (IMRT) for malignant mesothelioma. J. Thorac. Oncol. 4, S774.

Rusch, V. (2009). The MARS trial: resolution of the surgical controversies in mesothelioma? J. Thorac. Oncol. 4, 1189-1191.

Rusch, V. W., Rosenzweig, K., Venkatraman, E., Leon, L., Raben, A., Harrison, L., Bains, M. S., Downey, R. J., and Ginsberg, R. J. (2001). A phase II trial of surgical resection and adjuvant high-dose hemithoracic radiation for malignant pleural mesothelioma. J. Thorac. Cardiovasc. Surg. 122, 788-795.

Santoro, A., O’Brien, M. E., Stahel, R. A., Nackaerts, K., Baas, P., Karthaus, M., Eberhardt, W., Paz-Ares, L., Sundstrom, S., Liu, Y., Ripoche, V., Blatter, J., Visseren-Grul, C. M., and and Manegold, C. (2008). Pemetrexed plus cisplatin or pemetrexed plus carboplatin for chemonaïve patients with malignant pleural mesothelioma: results of the International Expanded Access Program. J. Thorac. Oncol. 3, 756-763.

Sartore-Bianchi, A., Gasparri, F., Galvani, A., Nici, L., Darnowski, J. W., Barbone, D., Fennell, D. A., Gaudino, G., Porta, C., and Mutti, L. (2007). Bortezomib inhibits nuclear factor-kappa B-dependent survival and has potent in vivo activity in mesothelioma. Clin. Cancer Res. 13, 5942-5951.

Scherpereel, A., Astoul, P., Baas, P., Berghmans, T., Clayson, H., de Vuyst, P., Dienemann, H., Galateau-Salle, F., Hennequin, C., Hillerdal, G., Le Péchoux, C., Mutti, L., Pairon, J.-C., Stahel, R., van Houtte, P., van Meerbeeck, J., Waller, D., and Weder, W. (2010). Guidelines of the ERS/ESTS for management of malignant pleural mesothelioma. Eur. Res. J. 35, 479-495.

Senan, S. (2003). Indications and limitations of radiotherapy in malignant pleural mesothelioma. Curr. Opin. Oncol. 15, 144-147.

Sørensen, J. B., Frank, H., and Sørensen, P. (2007). Phase II study of carboplatin and vinorelbine (i.v. and orally) first line chemotherapy in nonresectable malignant pleural mesothelioma (MPM). J. Thorac. Oncol. 2, S610-S611.

Sorensen, J. B., Sundstrom, S., Perell, K., and Thielsen, A. K. (2007). Pemetrexed as second-line treatment in malignant pleural mesothelioma after platinumbased first-line treatment. J. Thorac. Oncol. 2, 147-152.
Sorensen, P. G., Bach, F., Bork, B., and Hansen, H. H. (1985). Randomised trial of doxorubicin versus cyclophosphamide in diffuse malignant pleural mesothelioma. Cancer Treat. Rep. 69, 1431-1432.

Soysal, O., Karaoglanoglu, N., Demiracan, S., Topçu, S., Tatşepe, I., Kaya, S., Unlü, M., and Cetin, G. (1997). Pleurectomy/ decortication for palliation in malignant pleural mesothelioma: results of surgery. Eur. J. Cardiothorac. Surg. 11, 210-213.

Stahel, R. A., Weder, W., Felip, E., and ESMO Guidelines Working Group. (2009). Malignant pleural mesothelioma: ESMO clinical recommendations for diagnosis, treatment and follow-up. Ann. Oncol. 20(Suppl. 4), 73-75.

Steinman, R. M., and Dhodapkar, M. (2001). Active immunization against cancer with dendritic cells: the near future. Int. J. Cancer 94, 459-473.

Sterman, D. H., Recio, A., Carroll, R. G., Gillespie, C. T., Haas, A., Vachani, A., Kapoor, V., Sun, J., Hodinka, R., Brown, J. L., Corbley, M. J., Parr, M., Ho, M., Pastan, I., Machuzak, M., Benedict, W., Zhang, X. Q., Lord, E. M., Litzky, L. A., Heitjan, D. F., June, C. H., Kaiser, L. R., Vonderheide, R. H., Albelda, S.M., and Kanther, M. (2007). A phase i clinical trial of single-dose intrapleural IFN- $\beta$ gene transfer for malignant pleural mesothelioma and metastatic pleural effusions: high rate of antitumor immune responses. Clin. Cancer Res. 13, 4456.

Sterman, D. H., Recio, A., Vachani, A., Sun, J., Cheung, L., DeLong, P., Amin, K. M. Litzky, L. A., Wilson, J. M., Kaiser, L. R., and Albelda, S. M. (2005). Long-term follow-up of patients with malignant pleural mesothelioma receiving highdose adenovirus herpes simplex thymidine kinase/ganciclovir suicide gene therapy. Clin. Cancer Res. 11, 7444.

Sterman, D. H., Treat, J., Litzky, L. A., Amin, K. M., Coonrod, L., MolnarKimber, K., Recio, A., Knox, L., Wilson, J. M., Albelda, S. M., and Kaiser, L. R. (1998). Adenovirus-mediated herpes simplex virus thymidine kinase gene delivery in patients with localized malignancy: results of a phase 1 clinical trial in malignant mesothelioma. Hum. Gene Ther. 9, 1083-1092.

Strizzi, L., Catalano, A., Vianale, G., Orecchia, S., Casalini, A., Tassi, G., Puntoni, R., Mutti, L., and Procopio, A. (2001).Vascular endothelial growth factor is an autocrine growth factor in human malignant mesothelioma. J. Pathol. 193, 468-475.

Sugarbaker, D. J. (2006). Macroscopic complete resection: the goal of primary surgery in multimodality 
therapy for pleural mesothelioma. $J$. Thorac. Oncol. 1, 175-176.

Sugarbaker, D. J., Flores, R. M., Jaklitsch, M. T., Richards, W. G., Strauss, G. M., Corson, J. M., DeCamp MM, J. r., Swanson, S. J., Bueno, R., Lukanich, J. M., Baldini, E. H., and Mentzer, S. J. (1999). Resection margins, extrapleural nodal status, and cell type determine postoperative long-term survival in trimodality therapy for malignant pleural mesothelioma: results in 183 patients. J. Thorac. Cardiovasc. Surg. 117, 54-63.

Sugarbaker, D. J., Jaklitsch, M. T., Bueno, E., Richards, W., Lukanich, J., Mentzer, S. J., Colson, Y., Linden, P., Chang, M., Capalbo, L., Oldread, E., NeragiMiandoab, S., Swanson, S. J., and Zellos, L. S. (2004). Prevention, early detection, and management of complications after 328 consecutive extrapleural pneumonectomies. J. Thorac. Cardiovasc. Surg. 128, 138-146.

Swiss Group for Clinical Cancer Research. (2009). Neoadjuvant Chemotherapy and Extrapleural Pneumonectomy of Malignant Pleural Mesothelioma With Or Without Hemithoracic Radiotherapy. A Randomised Multicentre Phase II Trial (SAKK 1704). Available at: http://sakk.ch/en/ download/105 [accessed on Janaury 03, 2011].

Talbot, D. C., Margery, J., Dabouis, G., Dark, G., Taylor, H., Boussemart, H., Cadic, V., Pinel, M. C., Rivière, A., Ollivier, L., and Ruffié, P. (2007). Phase II study of vinflunine in malignant pleural mesothelioma. J. Clin. Oncol. 25, 4751-4756.

Teh, E., Fiorentino, F., Tan, C., and Treasure, T. (2010). A systematic review of lungsparing extirpative surgery for pleural mesothelioma. $J$. R. Soc. Med. 104, 69-80.

Thomas, A. M., Santarsiero, L. M., Lutz, E. R., Armstrong, T. D., Chen, Y. C., Huang, L. Q., Laheru, D. A., Goggins, M., Hruban, R. H., and Jaffee, E. M. (2004). Mesothelin-specific CD8(+) $\mathrm{T}$ cell response provide evidence of in vivo cross-priming by antigenpresenting cells in vaccinated pancreatic cancer patients. J. Exp. Med. 20, 297-306.

Treasure, T., Bliss, J., Tan, C., Entwisle, J., Waller, D., O'Brien, M., Coombes, G., Webster-Smith, M., Kilburn, L., Snee, M., Thomas, G., Darlison, L., Lang-Lazdunski, L., and Peto, J. (2010). Principal Results of the Feasibility Phase of the Mesothelioma and Radical Surgery Trial (MARS-feasibility). Available at: http://www.ncri.org. uk/ncriconference/2010abstracts/ abstracts/LB74.htm

Treasure, T., Waller, D., Swift, S., and Peto, J. (2004). Radical surgery for mesothelioma, the epidemic is still to peak and we need more research to manage it. BMJ328, 237-238. doi: 10.1136/ bmj.328.7434.237

Treasure, T., Waller, D., Tan, C., Entwisle, J., O'Brien, M., O'Byrne, K., Thomas, G., Snee, M., Spicer, J., Landau, D., Lang-Lazdunski, L., Bliss, J., Peckitt, C., Rogers, S., Marriage Née Denholm, E., Coombes, G., Webster-Smith, M., Peto, J., and Guy's and St Thomas' Hospital,London, UK.tom.treasure@ gmail.com. (2009). The mesothelioma and radical surgery randomised controlled trial: the MARS feasibility study. J. Thorac. Oncol. 4, 1254-1258.

UICC. (2006). Prognostic Factors in Cancer, 3rd Edn. eds M. K. Gospodarowicz, B. O'Sullivan, and L. H. Sobin. (Frankfurt: Wiley-Liss), 165-168. [ISBN-13978-0-470-03801-7].

Ung, Y. C., Yu, E., Falkson, C., Haynes, A. E., Stys-Norman, D., Evans, W. K., and Lung Cancer Disease Site Group of Cancer Care Ontario's Program in Evidence-based Care. (2006). The role of radiation therapy in malignant pleural mesothelioma: a systematic review. Radiother. Oncol. $80,13-18$

Van Meerbeeck,J.P., Gaafar, R., Manegold, C., Van Klaveren, R. J., Van Marck, E.A., Vincent, M., Legrand, C., Bottomley, A., Debruyne, C., Giaccone, G., European Organisation for Research and Treatment of Cancer Lung Cancer Group, and National Cancer Institute of Canada. (2005). Randomised phase III study of cisplatin with or without raltitrexed in patients with malignant pleural mesothelioma: an intergroup study of the European Organisation for Research and Treatment of Cancer Lung Cancer Group and the National Cancer Institute of Canada. J. Clin. Oncol. 23, 6881-6889.

Van Schil, P., Baas, P., Gaafar, R., Maat, A. P., Van de Pol, M., Hasan, B., Klomp, H. M., Abdelrahman, A. M., Welch, J., van Meerbeeck, J. P., and European Organisation for Research and Treatment of Cancer Lung Cancer Group. (2010). Trimodality therapy for malignant pleural mesothelioma: results from an EORTC phase II multicentre trial. Eur. Res. J. 36, 1362-1369.

Villano, J., Husain, A. J., Stadler, W. M., Hanson, L. L., Vogelzang, N. J., Kindler, H. L., and University of Chicago, Chicago, IL. (2004). A Phase II trial of imatinib mesylate in patients (pts) with malignant mesothelioma
(MM).Proc. Am. Soc. Clin. Oncol. 663. [abstract no. 7200].

Vogelzang, N. J., Rusthoven, J. J., Symanowski, J., Denham, C., Kaukel, E., Ruffie, P., Gatzemeier, U., Boyer, M., Emri, S., Manegold, C., Niyikiza, C., and Paoletti, P. (2003). Phase III study of pemetrexed in combination with cisplatin versus cisplatin alone in patients with malignant pleural mesothelioma. J. Clin. Oncol. 21, 2636-2644.

Waller, D. A., Morritt, G. N., and Forty, J. (1995). Video-assisted thoracoscopic pleurectomy in the management of malignant pleural effusion. Chest 5 , 1454-1456.

Wang, Y., Zhao, R., Chattopadhyay, S., and Goldman, I. D. (2002). A novel folate transport activity in human mesothelioma cell lines with high-affinity and specificity for the new-generation antifolate, pemetrexed.Cancer Res. 62, 6434-6437. [Erratum in: Cancer Res. 2003 Oct 15; 63(20):7004].

Watanabe, Y., Kojima, T., Kagawa, S., Uno, F., Hashimoto, Y., Kyo, S., Mizuguchi, H., Tanaka, N., Kawamura, H., Ichimaru, D., Urata, Y., and Fujiwara, T. (2010). A novel translational approach for human malignant pleural mesohtelioma: heparanaseassisted dual virotherapy. Oncogene 29, 1145-1154.

Webber, S., Bartlett, C. A., Boritzki, T. J., Hillard, J.A., Howland, E. F., Johnston, A. L., Kosa, M., Margosiak, S. A., Morse, C. A., and Shetty, B. V. (1996) AG337, a novel lipophilic thymidylate synthase inhibitor: in vitro and in vivo preclinical studies. Cancer Chemother. Pharmacol. 37, 509-517.

Weder, W., Kestenholz, P., Taverna, C., Bodis, S., Lardinois, D., Jerman, M., and Stahel, R. A. (2004). Neoadjuvant chemotherapy followed by extrapleural pneumonectomy in malignant pleural mesothelioma. J. Clin. Oncol. 22, 3451-3457.

Weder,W.,Stahel, R.A., Bernhard, J., Bodis, S., Vogt, P., Ballabeni, P., Lardinois, D., Betticher, D., Schmid, R., Stupp, R., Ris, H. B., Jermann, M., Mingrone, W., Roth, A. D., Spiliopoulos, A., and Swiss Group for Clinical Cancer Research. (2007). Multicentre trial of neo-adjuvant chemotherapy followed by extrapleural pneumonectomy in malignant pleural mesothelioma. Ann Oncol. 18, 1196-1202.

Yokokawa, J., Palena, C., Arlen, P., Hassan, R., Ho, M., Pastan, I., Schlom, J., and Tsang, K. Y. (2005). Identification of novel human CTL epitopes and their agonist epitopes of mesothelin. Clin. Cancer Res. 11, 6342-6351.
Zalcman, G., Margery, G., Scherpereel, A., Astoul, P., Monnet, I., Milleron B. J., Paule, L. M., André, M., MoroSibilot, D., Mazieres, J., on behalf of IFCT; CHU Côte de Nacre, Caen, France, HIA Percy, Clamart, France, CHRU Albert Calmette, Lille, France, University Hospital SainteMarguerite, Marseille, France, CHI, Creteil, France, Tenon University Hospital, Paris, France, IFCT, Paris, France, University Hospital Morvan and HIA, Brest, France, Hôpital Universitaire, Grenoble, France, and University Hospital Larrey, Toulouse, France. (2010). IFCT-GFPC-0701 MAPS trial, a multicenter randomized phase II/III trial of pemetrexed-cisplatin with or without bevacizumab in patients with malignant pleural mesothelioma. J. Clin. Oncol. 28, Abstract 7020. [ASCO Annual Meeting Proceedings].

Zhang, Y., Xiang, L., Hassan, R., Paik, C. H., Carrasquillo, J. A., Jang, B. S. Le, N., Ho, M., and Pastan, I. (2006). Synergistic antitumour activity of taxol and immunotoxin SS1P in tumour-bearing mice. Clin. Cancer Res. 12, 4695-4701.

Zucali, P. A., Ceresoli, G. L., Garassino, I., De Vincenzo, F., Cavina, R., Campagnoli, E., Cappuzzo, F., Salamina, S., Soto Parra, H. J., and Santoro, A. (2008). Gemcitabine and vinorelbine in pemetrexedpretreated patients with malignant pleural mesothelioma. Cancer 112, 1555-1561.

Conflict of Interest Statement: The authors declare that the research was conducted in the absence of any commercial or financial relationships that could be construed as a potential conflict of interest.

Received: 08 June 2011; accepted: 14 July 2011; published online: 22 August 2011.

Citation: Surmont VF, van Thiel ERE, Vermaelen Kand van MeerbeeckJP (2011) Investigational approaches for mesothelioma. Front. Oncol. 1:22. doi: 10.3389/ fonc.2011.00022

This article was submitted to Frontiers in Thoracic Oncology, a specialty of Frontiers in Oncology

Copyright (๑ 2011 Surmont, van Thiel, Vermaelen and van Meerbeeck. This is an open-access article subject to a nonexclusive license between the authors and Frontiers Media SA, which permits use, distribution, and reproduction in other forums, provided the original authors and source are credited and other Frontiers conditions are complied with. 